\title{
UN INTENTO DE REFORMA AGRARIA POR Y PARA LAS CLASES PRODUCTORAS: EL SEMANARIO DE AGRICULTURA Y ARTES DIRIGIDO A LOS PÁRROCOS (1797-1808)
}

Elisabel Larriba*

\section{El diálogo con el público: una prioridad}

El Semanario de Agricultura y Artes dirigido a los Párrocos fue creado en 1797, a petición del propio Príncipe de la Paz, que ejercía entonces el cargo de Primer Secretario de Estado'. Se trataba para los redactores de ese periódico semi-oficial de contribuir al fomento de la agricultura y de la industria, dando a conocer nuevos cultivos o nuevas técnicas, procedentes ya fuese de las distintas provincias de la Península, ya del extranjero. Para concretar sus objetivos habían determinado dirigirse a los principales interesados, o sea a las clases productoras: los campesinos y los artesanos. En una España en que (como subrayaban en el Prospecto de la obra) "los que labran no leen y los que leen no labran" ${ }^{\prime 2}$ tal elección podía parecer algo estrafalaria. Sin embargo, pese a las dificultades, los editores, llevados por un optimismo típicamen-

\footnotetext{
* Université de Provence, UMR Telemme.
}

1. Sobre el Semanario de Agricultura y Artes dirigido a los Párrocos, véase DIEZ RODRIGUEZ, F., Prensa agraria en la España de la llustración. 'El Semanario de Agricultura y Artes dirigido a los Párrocos' (1797-1808). Madrid 1980. Puede consultarse la colección completa de este periódico en la Biblioteca del Real Jardín Botánico de Madrid (signatura: P. 811) o en la Biblioteca Nacional (signatura: D / 2858). Esta colección consta de 599 números semanales publicados, sin interrupción, del 5 de enero de 1797 (fecha del primero) al 23 de junio de 1808 (fecha del último). Estos suelen tener 16 páginas y vienen encuadernados en 23 tomos (uno para cada seis meses). Existe también una antología que hemos publicado en colaboración con el Profesor Gérard DUFOUR: El Semanario de Agricultura y Artes dirigido a los Párrocos (17971808). Antología.Valladolid 1997.

2. "Prospecto", in Semanario de Agricultura.... Madrid 1797, tomo I, p. X to p.75 de nuestra antología). 
te ilustrado, pensaban poder entablar el diálogo con ese público atípico (que por regla general no tenía acceso al mundo del saber) confiando al clero, y principalmente al clero parroquial, el papel de intermediario cultural. Se trataba, a la espera de una reforma educativa que tan sólo podría efectuarse a largo plazo, de suplir las deficiencias de un sistema incapaz de proporcionar a los agricultores y artesanos un saber utilitario, es decir directamente relacionado con su actividad profesional. Así en una carta circular a los obispos (que se publicó en el periódico junto a la Introducción y el Prospecto), Godoy declaraba:

"Comprende el Rey que los efectos de un nuevo sistema de educación son ciertamente muy sólidos pero lentos, y de los cuales difícilmente se pudiera aprovechar la generación presente. Y aunque nunca abandonará S.M. el cuidado de proporcionar mayor felicidad a las generaciones futuras, desea al mismo tiempo con impaciencia ver en sus días que se propaguen del modo más fácil los conocimientos que puedan mejorar la suerte de sus vasallos agricultores y artistas. $Y$ tal ha sido su soberana intención al encargar la redacción del impreso cuyo prospecto acompaño a V.I. y que podrá dirigirse semanalmente a los Párrocos con el loable objeto de que, en las horas y ocasiones que lo permita su ministerio pastoral, se aprovechen ellos mismos, y como buenos padres de sus feligreses, se dediquen también a su felicidad temporal, instruyéndolos y extendiendo entre ellos, con el amor, dulzura que les es tan propia y les concilia su docilidad y respeto, los adelantamientos, industrias, invenciones y progresos que hagan las artes útiles, así en nuestra capital y provincias como en las naciones más adelantadas, a fin de que se utilicen de ellas los labradores y artistas y reformen sus antiguos métodos o adopten otros mejores en beneficio de sus propios intereses."

Asimismo, para ser asequibles a una mayoría, los artículos debían necesariamente ser redactados en un "lenguaje inteligible a los sencillos aldeanos". Por no haber respetado esa regla de oro, Domingo García Fernández (que formaba parte del primer equipo de redactores) fue apartado muy rápidamente de la empresa ${ }^{4}$. Entre las prioridades de los editores figuraba también el facilitar la comunicación entre la capital y la provincia así como entre las diferentes regiones de España. Para romper un aislamiento endémico que dificultaba sobremanera el desarrollo económico del país, deseaban hacer del periódico un lugar de intercambio abierto a todos, una obra colectiva en la que el público dejaría de ser un mero receptor para convertirse en un verdadero interlocutor. En uno de los primeros artículos del Semanario de Agricultura y Artes... (el número 12), los editores, tras rendir homenaje a todos los que ya les habían manifestado "su anhelo de contribuir con sus luces al bien de la causa pública, y a esparcir noti-

3. Carta del Príncipe de la Paz a los obispos, San Lorenzo, 28 de noviembre de 1796, in Semanario de Agricultura... 1797, tomo I, p. VI (o p. $71-72$ de nuestra antología).

4. Véase la introducción de nuestra antología, p. 18. 
cias útiles particularmente a los apreciables labradores" ${ }^{5}$, daban su propia definición del periódico con el que soñaban. Así, remitiendo a un clérigo, don Pedro Antonio Fernández (rector de Santiago en Albarracín), que en varias ocasiones les había informado por carta de los experimentos llevados a cabo en su feligresía respecto a la fabricación del jabón y les prometía más noticias, concluían:

"Si hay muchos que sigan el ejemplo de este celoso eclesiástico en comunicarnos los adelantamientos e industrias de su país, se llenarán completamente las esperanzas del gobierno, y será el Semanario un medio por el que unos a otros nos comunicaremos nuestros adelantamientos en beneficio de la causa pública y de cada uno en particular"

Pero, al solicitar la participación del público, los editores no aspiraban exclusivamente a ampliar su red informativa. Rehuyendo cualquier forma de protagonismo, deseaban siempre que fuese posible ceder la palabra a un público que cabía seducir. De ahí la publicación de numerosas cartas (reales o a veces ficticias) que daban a la obra dinamismo, amenidad y que podían ser consideradas como índices del interés suscitado por la obra entre la población. Obviamente, el recurso al género epistolar distaba mucho de constituir una novedad en la España dieciochesca y varios periódicos se dejaron Ilevar por ese fenómeno de moda. Sin embargo, pocos fueron los que, como el Semanario de Agricultura y Artes..., intentaron hacer del diálogo con el público una prioridad. Así, entre el 5 de enero de 1797 y el 23 de junio de 1808, dieron cabida a unas 252 cartas que representan el 9,6\% de la obra e incluso publicaron 2 números constituidos exclusivamente por cartas. En el 99, con fecha del 22 de noviembre de 1798, figuraban la de Don Estebán Boutelou (jardinero mayor de S.M. en Aranjuez) sobre el cultivo de espárragos ${ }^{7}$, la de Juan Marcos Serrano (vecino de Cañaveral, en Extremadura) sobre las enfermedades de los garbanzales ${ }^{8} y$ otra sobre la manteca, firmada por Juan Mateo de Gastaca y Vengoa, residente en Villarejo de Salvanes (provincia de Toledo) ${ }^{9}$. En el 209, publicado el 1 de enero de 1801, se podía leer un artículo único titulado Carta de un labrador de Sevilla sobre la mejor administración de las grandes haciendas ${ }^{10}$.

5. Semanario de Agricultura.... tomo I, $\mathrm{n}^{\circ} 12,23$ de marzo de 1797, p. 190.

6. Semanario de Agricultura.... tomo I, n 12, 23 de marzo de 1797, p. 192.

7. "Carta de Don Estebán Boutelou, jardinero mayor de S.M. en Aranjuez, sobre el cultivo de espárragos, Aranjuez, 6 de octubre de 1798", in Semanario de Agricultura.... tomo IV, n99, 22 de noviembre de 1798, pp. 321-334.

8. "Carta sobre las enfermedades de los garbanzales, Cañaveral, 22 de julio de $1798^{\prime \prime}$, in Semanario de Agricultura.... tomo IV, n99, 22 de noviembre de 1798, pp. 334-335.

9. "Carta sobre la manteca de la leche", in Semanario de Agricultura... tomo IV, n99, 22 de noviembre de 1798, pp. 335-336.

10. "Carta de un labrador de Sevilla sobre la mejor administración de las grandes haciendas, por Eleuterio Vero, Sevilla, 10 de junio de 1800", in Semanario de Agricultura.... tomo IX, $n^{\circ} 209,1$ de enero de 1801, pp. 3-8. 


\section{Un entusiasmo de corta duración}

Sin embargo, pese a los esfuerzos de los editores, la participación del público como redactor no siempre fue la esperada. Como demuestra el gráfico que viene a continuación, ésta sufrió a lo largo del tiempo importantes variaciones:

Cartas publicadas en el Semanario de Agricultura y Artes... entre 1797 y 1808

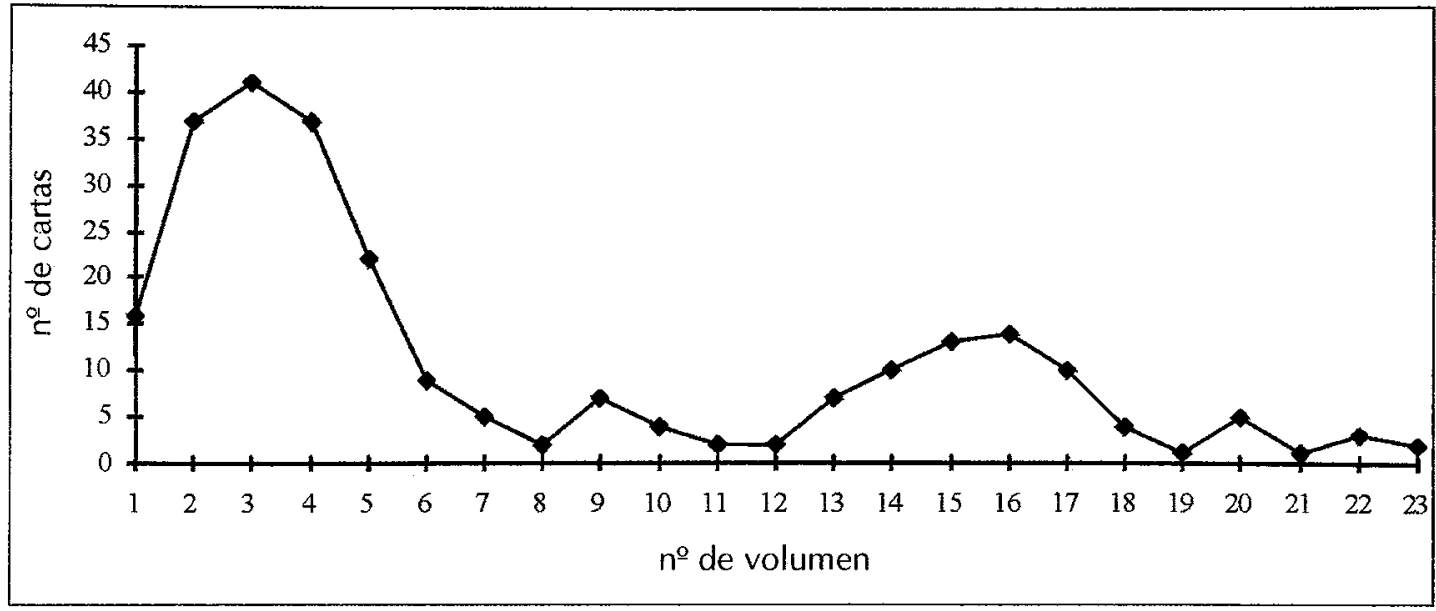

El Semanarario de Agricultura y Artes..., que gozaba del apoyo incondicional de las autoridades y cuya salida fue anunciada a bombo y platillo ${ }^{11}$, tuvo en un principio una acogida bastante favorable. Así, varios lectores decidieron de inmediato aunar sus esfuerzos al de los editores haciéndoles partícipes de sus observaciones o experimentos. Con lo cual el número de cartas publicadas sufrió un incremento constante hasta mediados de 1798 en que se alcanzó un máximo (jamás igualado) de 41 participaciones que representaban un total de 106 páginas, o sea el 25,5\% del correspondiente volumen. A estas alturas, los editores parecían haber conseguido ofrecer "a los hombres buenos y amantes de los adelantamientos de su nación un conducto por donde pudiesen comunicar a todos las observaciones y progresos que consiguiesen en sus prácticas rurales ${ }^{\prime 12}$. El Semanario de Agricultura y Artes... se había convertido en un lugar de expresión abierto a todos, gracias al cual cada uno podía pedir

11. Para dar a conocer el periódico se esparcieron unos 22300 ejemplares del Prospecto (12 500 en España y 9800 en las Indias). Asimismo el referido Prospecto fue publicado íntegro primero en la Gaceta de Madrid del 7 de enero de 1797 y luego en el Memorial literario de abril y de mayo del mismo año. A la par el propio Godoy lo comunico, de orden del Rey, a todos los prelados tanto de la Península como de los territorios de Ultramar. Véase al respecto la introducción de nuestra antología ("El nacimiento de un periódico", pp. 9-11).

12. "Diálogo entre D.C. y D.A. sobre el modo más conveniente de publicar el Semanario de agricultura para que sea útil", in Semanario de Agricultura.... tomo VII, $n^{\circ} 165,27$ de febrero de 1800, p. 143 (o p. 138 de nuestra antología). 
o proporcionar informaciones. Así lo había entendido Joaquín González Palomino, cura párroco de Cereceda de la Sierra (lugar de 285 habitantes en la provincia de Salamanca ${ }^{13}$ ). Varios de sus parroquianos se encontraban en la incapacidad de trabajar la tierra debido a la ceguera de numerosos bueyes afectados por un mal desconocido. Ante la gravedad de la situación, contaba con el apoyo de los editores para informarle de la existencia de eventuales remedios. Su carta, inserta en el número 48 del 30 de noviembre de $1797^{14}$, dio lugar a una respuesta publicada a continuación en la que solicitaban del eclesiástico datos complementarios (como por ejemplo el tipo de comida proporcionado a las reses) y lanzaban a la par un llamamiento a los lectores del periódico: "Convidamos a todos los que se interesen en el bien de sus semejantes y sepan del modo de curar esta enfermedad en los bueyes a que nos remitan sus observaciones, a fin de que comunicándolas al público, se pueda remediar en los pueblos en que se padezca"15. El párroco de Cereceda, que no escatimó sus esfuerzos, accedió a la demanda de los editores y el fruto de sus indagaciones fue publicado el 22 de febrero de $1798^{16}$. Su carta provocó un nutrido comentario por parte de los responsables del periódico que, en su artículo, proporcionaron varios consejos susceptibles de cortar la enfermedad. Asimismo rindieron homenaje al celoso eclesiástico que, conmovido por el desamparo de sus feligreses, había manifestado el mayor interés por cuestiones totalmente ajenas a su ministerio ${ }^{17}$. Al referirse a las informaciones (no siempre satisfactorias) libradas por el párroco declaraban: "merecen sin embargo nuestra estimación, porque hasta ahora se han considerado estas ideas por nuestros mayores, como ajenas de un hombre de carrera. ¡O tiempos! ¡O costumbre!"18. A continuación, un lector de Ponferrada (Galicia), identificado por sus iniciales (L.T.), facilitaba una receta para el mal de ojos que había surtido los mejores efectos en los hombres y que, quizás, podría resultar eficaz para los animales. Su carta, con fecha del 1 de diciembre de 1797, fue redactada, por tanto, tan sólo un día después de publicarse el número $48^{19}$. Esta indujo a su vez los comentarios de un profesor de veterinaria que confirmaba lo anteriormente expuesto con el respaldo de argumentos ciéntificos ${ }^{20}$. Con lo cual el punto de vista de un especialista complementaba el de un pro-

13. Cf. Censo de Floridablanca. Madrid 1787. Los originales pueden consultarse en la Real Academia de la Historia y (exclusivamente para Cataluña) en la Biblioteca del Palacio Real. También existe un trabajo realizado por el INE en que vienen recopilados todos los datos que figuran en el referido censo: Censo de 1787 "Floridablanca". Madrid 1987.

14. "Carta del párroco de Cereceda", in Semanario de Agricultura... tomo II, n48, 30 de noviembre de 1797, p. 338.

15. "Carta del párroco de Cereceda", p. 339.

16. Semanario de Agricultura..., tomo III, $n^{\circ}$ 60, 22 de febrero de 1798, pp. 119-121.

17. Semanario de Agricultura..., tomo III, $n^{\circ} 60,22$ de febrero de 1798, pp. 121-123.

18. Semanario de Agricultura..., tomo III, $n^{\circ} 60,22$ de febrero de 1798, p. 121.

19. Semanario de Agricultura..., tomo III, $n^{\circ} 60,22$ de febrero de 1798, pp. 123-124.

20. Semanario de Agricultura..., tomo III, $\mathrm{n}^{\circ}$ 60, 22 de febrero de 1798, pp. 124-125. 
fano. Finalmente, el artículo sobre la ceguera del ganado vacuno concluía con la carta de Miguel Bravo, cura de Blocona (lugar de 202 habitantes en la provincia de Soria ${ }^{21}$ ), que comunicaba a los editores el método empleado, hacía unos años, por feligreses suyos para curar bueyes que, tal como sucedía en Cereceda, sufrían del mal de ojos ${ }^{22}$. Esa multiplicidad de reacciones ante el problema planteado por un individuo nos ofrece pues una prueba fehaciente de la interactividad de un periódico al servicio de su público. Y esa interactividad, que confiere a la obra un cariz tan peculiar, siempre fue alentada por los editores que multiplicaron los llamamientos a los lectores e intentaron crear un clima de emulación presentando la colaboración a la redacción del Semanario... como un deber patriótico, adelantándose a lo que, unos años después, caído ya el Príncipe de la Paz, será considerado como lo propio del ciudadano. Así las observaciones de un labrador de Jerez de los Caballeros publicadas en julio de $1797^{23}$ eran introducidas por la siguiente nota: "Don Francisco Felix de Velasco, labrador de Jerez de los Caballeros, provincia de Extremadura, de setenta años de edad, que se ha ocupado toda su vida en la labranza y la cría de ganados, ha comunicado al Semanario con la mayor sencillez y verdad cuanto ha llegado a comprender sobre la economía rural de su país, y nos ha parecido conveniente publicar sus observaciones en los mismos términos provinciales que usa, a fin de animar a otros hacendados instruidos de las provincias del reino y dominios ultramarinos de S.M. a que nos comuniquen iguales observaciones por las ventajas que deben resultar a todos del conocimiento de cuantos frutos se cultivan en los dominios del Rey y de los métodos que se observan en las labores." Sin embargo, pese a los esfuerzos del equipo redactor y a unos primeros resultados esperanzadores, la participación del público inició a mediados de 1798 (al año y medio de ser creado el periódico) un declive estremecedor. Las cartas publicadas entre 1797 y 1798 representan el $52 \%$ de la correspondencia inserta en el Semanario..., cuando este periódico perduró unos doce años. La tendencia parece invertirse entre 1803 y 1804, periodo crítico que precede el traspaso del Semanario... al Real Jardín Botánico de Madrid $^{24}$ y durante el cual los editores intentaron dar un nuevo impulso a la obra, ya que el número de cartas publicadas por semestre, que en $1802^{25}$ tan sólo era de dos, pasó a 14 en los seis útimos meses de $1804^{26}$. Sin

21. Cf. Censo de Floridablanca. Madrid 1787.

22. Semanario de Agricultura..., tomo III, $n^{\circ} 60,22$ de febrero de 1798, p. 126.

23. "Productos del terreno de la Ciudad de Jerez de los Caballeros y métodos de beneficiarle" (carta remitida a los editores por Franciso Felix de Velasco el 27 de febrero de 1797), in Semanario de Agricultura..., tomo II, $n^{\circ} 28$ (13 de julio de 1797), pp. 16-19, $n^{\circ} 29$ (20 de julio de 1797), pp. 31-35 y $n^{\circ} 30$ (27 de julio de 1797), pp. 41-49.

24. Véase al respecto en la introducción de nuestra antología "El traspaso del Semanario de Agricultura y Artes... al Real Jardín Botánico y el segundo equipo de redactores", pp. 25-33.

25. Los volúmenes correspondientes son los XI (enero a junio de 1802) y XII (julio a diciembre del mismo año). Véase el gráfico anterior.

26. Volumen XVI (julio a diciembre de 1804). Véase el gráfico anterior. 
embargo esa mayor implicación del público como colaborador fue en parte ficticia. Efectivamente, los editores, con el fin de disimular el desapego de gran parte sus corresponsales, utilizaron entonces varias cartas que les habían sido remitidas hacía años. Entre otros casos, la Noticia de la agricultura y economía de Asturias, que se debía a un párroco de aquel Principado identificado tan sólo por sus iniciales (L. J. B. de M. y Q.), había sido redactada el 20 de diciembre de 1797 y fue publicada en marzo de $1803^{27}$. Finalmente, en 1805, cuando se produjo el cambio direccional, escasearon considerablemente las cartas de los lectores, en gran parte como consecuencia de la política de los nuevos redactores. El periódico, concebido inicialmente como una obra de divulgación, se convirtió paulatinamente en el órgano de expresión del Real Jardín Botánico, es decir en una revista ciéntifica hecha por y para especialistas $^{28}$. Ello no impide que durante varios años el público fue considerado como un interlocutor privilegiado e incluso como un colaborador más. Y, como hemos visto, varios fueron los lectores que aceptaron la invitación al diálogo lanzada por los editores.

\section{La participación del clero}

Ahora bien ¿quiénes fueron los 186 individuos que entablaron una correspondencia con los redactores y cuáles fueron las temáticas que abarcaron? Entre ellos, figuraban tan sólo 54 eclesiásticos (el 29\%) que firmaron 89 de las 252 cartas publicadas (el $35,3 \%$ ), lo que no pudo satisfacer a unos editores que habían escogido al clero como principal elemento de difusión de su periódico. Asimismo, como se puede comprobar en el gráfico que viene a continuación, fueron los primeros en perder el entusiasmo suscitado por la creación del Semanario del Agricultura y Artes... Su colaboración sufrió una disminución sensible a principios de 1798 y a partir de 1799 pasó a ser simbólica hasta tal punto que en 9 de los 23 volúmenes publicados ${ }^{29}$ no se encuentra el menor rastro de su participación ${ }^{30}$.

27. Semanario de Agricultura..., tomo XIII, $\mathrm{n}^{\circ} 323,10$ de marzo de 1803, pp.145-153 y $\mathrm{n}^{\circ}$ 324, 17 de marzo de 1803, pp. 161-167.

28. Sobre los cambios generados por el cambio direccional de 1805, véase en la introducción de nuestra antología: "Un mismo título, dos concepciones distintas del Semanario de Agricultura y Artes...", pp. 33-36.

29. Como se puede comprobar en el gráfico se trata de los volúmenes VIII (junio a diciembre de 1800), IX (primer semestre de 1801), XI y XII que corresponden a 1802, XVII y XVIII que cubren el año 1805 y finalmente XXI a XXIII que abarcan el periodo que va de enero de 1807 hasta junio de 1808.

30. Sobre la participación del clero a la redacción del Semanario de Agricultura y Artes... véase: LARRIBA, Elisabel, "Contribution du clergé à la rédaction du Semanario de Agricultura...", in L'Espagne du XVIIle siècle. Economie, societé, idéologie et culture. Actes des journées d'étude sur "Ville et campagne" et Cartas marruecas des 5 et 6 décembre 1997. Saint-Etienne 1997, pp. 217-233. 
Evolución comparativa del número de cartas publicadas en el Semanario de Agricultura y Artes...

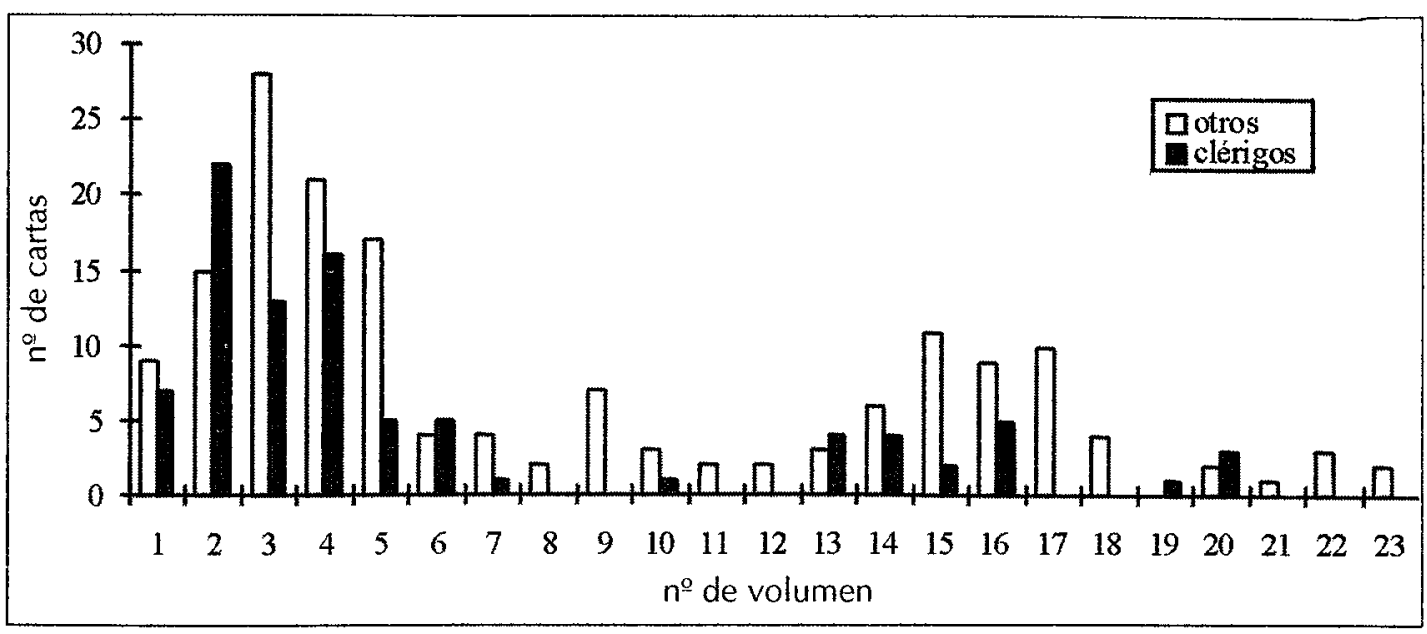

En hartas ocasiones la patente indiferencia de gran parte del clero hacia el Semanario de Agricultura y Artes... fue presentada por los editores como una de las mayores causas del fracaso de la empresa ${ }^{31}$. Sin embargo encontraron entre sus filas a unos de sus colaboradores más entusiastas. Convencidos de que el interesarse por cuestiones agrarias y por el bienestar material de sus feligreses no era incompatible con su ministerio, sino todo lo contrario, aceptaron con placer el papel de agente transmisor que se les había confiado. Entre esos celosos clérigos figuraba por ejemplo Francisco Hernández Gonzalez, beneficiado de Alba de Tormes, que en 1797 "escribe a los Editores del Semanario que ha hecho viajes a varios pueblos de España para enterarse y aprender cuanto se ha adelantado en diversos ramos de agricultura y de industria, llevando intención de ponerlos después en práctica, y de enseñar a sus consúbditos, como es tan propio de su estado; y añade que la persuasión de que las ocupaciones premian por sí ampliamente a los hombres activos, pues les proporcionan mucha variedad de goces y conveniencias, y disipan la miseria, que unida a la ociosidad es el origen de los vicios, le hizo perseverar en su loable empeño con la mayor constancia" ${ }^{32}$. Una vez finalizado su recorrido contribuyó activamente al desarrollo económico de la comarca, lo que le valió la admiración de los editores del Semanario... y también el recelo de algunos de sus conciudadanos como demuestran los comentarios que cierran el artículo: "Si hubiera muchos en España que se dedicasen con celo verdaderamente patriótico a propagar estas

31. Véase al respecto en la introducción de nuestra antología: "La indiferencia del clero", pp. 51-58; LARRIBA, Elisabel, "Contribution du clergé a la rédaction du Semanario de Agricultura..." y "L'échec du Semanario de Agricultura...", in Le Public de la presse en Espagne à la fin du XVIIle siècle (1781-1808). París 1998, pp. 254-275.

32. "Extracto de una carta a los Editores", in Semanario de Agricultura..., tomo I, $n^{\circ} 21,25$ de mayo de 1797, p. 330. 
enseñanzas harían mucho mayor beneficio a las familias y a la causa pública que si se hiciesen muchas limosnas con las que, si no hay gran prudencia en repartirlas, se fomenta la ociosidad que reposa sobre una caridad mal entendida. El autor de esta carta sólo ha comunicado a los Editores sus desvelos con el fin de que se le auxiliase para vencer la oposición que hallan en algunos pueblos sus útiles pensamientos..." ${ }^{\prime 33}$. En efecto, no podía ser del agrado de todos, y menos de los miembros de una élite social y económica cuyo fervor patriótico no llegaba a tanto, el hecho de que un eclesiástico introdujera nuevos cultivos, plantase árboles, ofreciera construir un molino, una máquina de aparvar, un potro para herrar, propusiera desviar un arroyo cercano para poder irrigar ciertas fincas, proporcionar a sus feligreses plantas medicinales de las que carecían, "enseñar a los pastores el uso de una ballesta o torno para hacer con maderas de encina, roble y fresno, varias cosas como peones o trompos, boliches, cabos de lesnas, de martillos, y otros artículos fáciles, proporcionándoles las herramientas para ello; darles alicates, y enseñarles a engastar rosarios, hacer corchetes para que no se gasten los de Inglaterra; hacer jaulas, ratoneras y otras cosas de arambre; a otros darles moldes y modo de hacer y vaciar botones, cruces, hevillas y otros artículos de plomo y estaño; a otros instruirles para que hagan botones de hueso, de asta, de madera, y hormillas..." ${ }^{34}$. El cura de Linares (villa de 903 habitantes en la provincia de Salamanca ${ }^{35}$ ), que llegó a ser un colaborador asiduo de los redactores ${ }^{36}$, estaba igualmente convencido de que los eclesiásticos, los primeros, habían de hacer cuanto pudieran para

33. Semanario de Agricultura..., tomo I, $n^{\circ} 21,25$ de mayo de 1797, p. 332.

34. "Extracto de una carta a los Editores", in Semanario de Agricultura..., tomo I, n 21,25 de mayo de 1797, pp. 330-331.

35. Cf. Censo de Floridablanca. Madrid 1787.

36. El cura de Linares se dio a conocer con una carta referente a la fabricación del pan de patatas que redactó el 5 de febrero de 1797 (al mes de parecer el periódico) y que fue publicada en el $n^{\circ} 13$ del 30 de marzo del mismo año (tomo I, pp. 203-206 o pp. 85-88 de nuestra antología). Tras este artículo que fue el primero de una larga serie, los redactores, que llegaron a considerar al cura de Linares como el especialista de las patatas, solicitaron sus consejos y su colaboración en reiteradas ocasiones. En octubre del mismo año publicaron otro artículo suyo titulado Carta del cura de Linares sobre el cultivo y aprovechamiento de las patatas que cubre 5 números consecutivos ( $n^{\circ} 41,5$ de octubre de 1797, pp. 222-227; $n^{\circ} 42,19$ de octubre, pp. $229-236 ; n^{\circ} 43,26$ de octobre, pp. 245-53; $n^{\circ} 44,2$ de noviembre, pp. 261-269 y $n^{\circ} 45,9$ de noviembre, pp. 277-282). Otra carta suya fue publicada en noviembre de 1799 ("El cura de Linares a los Editores del Semanario de Agricultura", in $n^{\circ} 151,21$ de noviembre de 1799, pp. 330-333). En el $n^{\circ} 156$, con fecha del 26 de diciembre del mismo año (pp. 401-402), se podía leer la "Carta del Cura de Linares sobre el aumento que en su feligresía ha tenido en estos años el cultivo de patatas". El n 241 (13 de agosto de 1801, pp. 97-106) principiaba con una "Carta del cura de Linares en el obispado de Salamanca" y el artículo "Del maíz cuarenteno" que figura en el $n^{\circ} 352$ con fecha del 29 de septiembre de 1803 (p. 208) Ileva también la firma del eclesiástico. Con una participación a 10 números y un total de 59 páginas publicadas, el cura de Linares fue el principal corresponsal de los redactores tanto entre los clérigos como entre los láicos. 
luchar contra la tremenda miseria econónomica del pueblo. Con lo cual, en uno de sus artículos sobre el cultivo y aprovechamiento de las patatas, se lanzó en una verdadera diatriba en contra de todos los que condenaban la implicación directa de representantes del clero en asuntos al parecer ajenos a su sagrado ministerio y se olvidaban de que uno de los principales deberes de "un buen ciudadano y fiel vasallo del Rey", sea cual sea su estado, estribaba en ser útil a su prójimo. "Antes de entrar en materia -escribía- he de decir que por más que los hombres de juicio esten persuadidos de la utilidad general que resulta y debe resultar a la nación de escritos de la naturaleza del semanario de agricultura, no faltan todavía Ostrogodos que muy pagados de hombres sesudos, no pueden digerir que haya curas que dejen de la mano al Padre Larraga para leer al Padre Vaniere; y erizados de latines, textos y comentarios en folio, no quieren entender que el cura no se desprende por su oficio de las obligaciones de un buen ciudadano y fiel vasallo del Rey. Parece increíble, pero ello es cierto, que también hay todavía muchos que almuerzan Petavios, y cenan Papebrochios, los cuales tienen por más importante el saber cómo se llamaba la abuela del que presidió el Concilio de Riminí, que los medios de aumentar y mejorar nuestros alimentos, y con ellos nuestra existencia y el alivio de nuestras necesidades. Dejémosles en sus sandeces, y vamos a tratar de un punto importantísimo para evitar el hambre en los años escasos, a lo cual si pudiera yo contribuir, me daría por mucho más satisfecho que con cuanto saben estos sapientísimos varones, y que con todos los distintivos que ha inventado el diccionario de la Heráldica" ${ }^{\prime 37}$. El mismo celo patriótico animaba a un párroco suscriptor del obispado de Sigüenza, que era aficionado a la lectura de libros de agricultura y que, dos veces a la semana, se reunía en su casa con varios feligreses suyos para comentarles y explicarles los artículos publicados en el Semanario..., obra imprescindible, según él. Así en su carta, publicada el 13 de julio de 1797, se ofrecía como corresponsal, exhortaba a los editores a proseguir en su loable tarea y declaraba sin rodeos: "créanme que el peor Semanario importa más que muchos tomos de a folio que yo me sé, y que todo lo que encierran las cabezas de muchos, que la gente cree muy sabios, y que yo conozco muy bien lo que son ${ }^{\prime 38}$. Este no fue un caso aislado como lo demuestra, por ejemplo, la nota que concluía el número 21 del 25 de mayo de 1797 en que los responsables de la obra rendían homenaje a "los beneméritos párrocos de Escalonilla, de Santiago de Turegano, de Villoria, Sondelpuerto, de Matarrubia, de Hardales, los del partido de Semontano, obispado de Huesca, Don Judas Joseph de Cabriada, presbítero, y otros muchos curas y eclesiásticos [que] han avisado a los Editores del Semanario el sumo gusto con que lo leen a sus feli-

37. "Carta del cura de Linares sobre el cultivo y aprovechamiento de las patatas", in Semanario de Agricultura..., tomo II, $n^{\circ} 41,10$ de diciembre de 1797, p. 223.

38. "Carta a los Editores", por un párroco suscriptor del obispado de Siguenza, in Semanario de Agricultura..., tomo II, $\mathrm{n}^{\circ} 28,13$ de julio de 1797, p. 20. 
greses comunicando algunos al mismo tiempo varias observaciones sobre la agricultura, que se irán insertando según haya cabimiento. ${ }^{139}$ Conforme a lo ideado, el público del periódico rebasaba los límites de un mero lectorado. De una enseñanza escrita asequible a una minoría se pasaba a una enseñanza basada en la práctica y la oralidad, es decir asequible a todos gracias a la participación de eclesiásticos convertidos en maestros de agricultura y artes. Años más tarde, en 1804, Francisco de Villalán, clérigo de Fontihoyuelo de Campos (villa de 401 habitantes en la provincia de León ${ }^{40}$ ), fiel a ese ideal, en un artículo en que hizo varias propuestas para mejorar la agricultura, fue hasta proponer que "tuviesen los Párrocos y Beneficiados la mitad de sus rentas en tierras de labor que no distasen una milla del pueblo, lo que les ocuparía útilmente en muchos ratos." Gracias a esa medida "se harían agricultores prácticos que enseñarían después de la buena moral la mejor agricultura" ${ }^{41}$. Sin embargo, pese a unos resultados aparentemente satisfactorios, el clero parroquial seguía sumamente dividido. Como subrayaba en 1803 el cura de Turienzo de los Caballeros (lugar de 268 almas en la provincia de León ${ }^{42}$ ), que invitaba sus homólogos a leer el periódico desde el púlpito, "a los párrocos sabios que han contribuido a hacer apreciables y útiles los Semanarios de agricultura" se oponían los que "haciendo mofa de sus oportunas instrucciones, acaso sin haber leído uno, retraen a no pocos con su ceñuda magistralidad y poltronería de que presenten noticias muy importantes para la prosperidad del estado" ${ }^{\prime 43}$. Las cartas de eclesiásticos publicadas y a veces comentadas por los redactores reflejaban perfectamente esa realidad. Sus autores no siempre se limitaron a dar constancia de sus observaciones o de sus esfuerzos para contribuir a la difusión del periódico. A menudo, sirviendo probablemente tanto sus intereses personales como los de los redactores, aprovecharon la ocasión para denunciar públicamente a los miembros del clero que, lejos de seguir su conducta, se desinteresaron por completo de una empresa respaldada por las autoridades ${ }^{44}$. Fuesen cuales fueran los motivos que indujeron a ciertos eclesiásticos a colaborar en la redacción del periódico, sus artículos tuvieron a veces un impacto nada desdeñable. Por ejemplo, la publicación en marzo de 1797 de una carta en la que el ya citado cura de Linares exponía el modo de hacer pan de patatas con el fin de ali-

39. Semanario de Agricultura..., tomo I, $\mathrm{n}^{\circ} 21,25$ de mayo de 1797, p. 336.

40. Cf. Censo de Floridablanca. Madrid 1787.

41. "Sobre el modo de mejorar nuestra agricultura - Carta de D. Francisco de Villalán Extracto", in Semanario de Agricultura..., tomo XVI, n 395, 26 de julio de 1804, p. 50.

42. Cf. Censo de Floridablanca. Madrid 1787.

43. "Del fomento de los plantíos, y modo de hacer sidra en Asturias - Extracto de una carta del cura de Turienzo de los Caballeros", in Semanario de Agricultura..., tomo XIV, n³40, 7 de julio de 1803, p. 3.

44. Sobre la ambigüedad de las cartas publicadas por ciertos eclesiásticos véase nuestro artículo sobre la "Contribution du clergé à la rédaction du Semanario de Agricultura...", pp. $229-232$. 
viar a los pobres durante los años de escase ${ }^{45}$ dio lugar a toda una serie de experimentos por parte de los lectores. Un mes después se podía leer en una nota: "El Administrador de Correos de Belmonte avisa que hizo pan de patatas por el método del Cura de Linares, publicado en el Núm. 13 que le salió excelente, que le distribuyó entre varias personas, y que todas le tuvieron por pan de trigo. Añade que no será él solo el que haga la experiencia, porque muchos se han informado ya para hacerlo en sus casas, con lo cual se propagará el cultivo de las patatas, que sólo hace dos años que se conoce en aquel pueblo de la Mancha".46. Asimismo, en una carta que figura en el número 92 de noviembre del 1798, un cura que, tras leer el Semanario..., había introducido en su parroquia el cultivo de las patatas manifestaba todo su agradecimento tanto al cura de Linares como a los redactores, en nombre y a petición de sus feligreses que habían podido verificar la utilidad de las informaciones difundidas por el periódico ${ }^{47}$.

\section{Unos corresponsales en su mayoría láicos}

Como ya vimos, pese a los esfuerzos realizados para movilizar al clero, la mayor parte de los corresponsales (132, o sea el $71 \%$ ) no formaban parte de ese colectivo. Los datos proporcionados sobre esos colaboradores son a menudo escasos, sea por voluntad propia (algunos prefirieron conservar el anonimato), sea por decisión de los redactores que mediante la publicación de cartas ofrecían a los lectores retratos prototípicos de hombres que, al servicio de su nación, se desvelaban para proponer mejoras económicas y manifestaban ser apasionados defensores del periódico. De esos 132 individuos, 82 indicaron sus nombres y apellidos. Sin embargo, conocemos a 21 tan sólo por sus iniciales, 16 vienen identificados únicamente por su profesión o calidad, 7 se presentaron como suscriptores del periódico y 6 sencillamente como "vecino de".

De los 56 cuya actividad laboral se menciona o hemos podido determinar, 26 tenían una relación directa con el trabajo de la tierra. Entre ellos figuraban 13 labradores, 2 cosecheros, 1 jardinero así como 7 hacendados, 1 catedrático de agricultura y 2 botánicos. Es decir que tanto el humilde agricultor como el holgado propietario, tanto el que vivía de la tierra como el científico, podían y hasta debían expresarse en el Semanario de Agricultura y Artes... Con lo cual, deseosos de demostrar que el periódico rehusaba cualquier tipo de elitismo, que se interesaba por todos a la par que interesaba a todos, los redactores no dudaron en insertar en sus números cartas de autoría dudosa como por ejem-

45. "Carta a los Editores" por el Cura de Linares, 5 de febrero de 1797, in Semanario de Agricultura..., tomo I, $n^{\circ} 13,30$ de marzo de 1797, pp. 203-206. [Este artículo viene también reproducido en nuestra antología, pp. 85-88.]

46. "Nota", in Semanario de Agricultura..., tomo I, $\mathrm{n}^{\circ}$ 17, 27 de abril de 1797, p.263.

47. "Carta de un párroco sobre varios experimentos en agricultura", in Semanario de Agricuitura..., tomo IV, $\mathrm{n}^{\circ}$ 92, 4 de octubre de 1798. 
plo la que "un probe labrador de tres leguas de Madrí" dirigió en febrero de 1798 a los "Señores Aditores". En lugar de limitarse a dar cuenta de la información, prefirieron publicar un escrito que reproducía el lenguaje popular y abundaba en faltas ortográficas ${ }^{48}$. Unos meses después, en septiembre del mismo año, el lector descubría la carta de otro labrador de las cercanías de Madrid, artículo de 8 páginas en el que el autor (J.C.A.M.) exponía con un rigor científico y una pulcritud admirables la diferencia de rentabilidad que suponía el trabajar la tierra con bueyes o con mula ${ }^{49}$. Al retrato de un humilde campesino de parva educación sucedía el de un hombre cultivado que, por decisión propia, había abandonado el bullicio de la capital y "el mundanal ruido" para dedicarse ufanoso a las labores del campo que le permitían ser verdaderamente útil, presentándose a sí mismo en una introducción que no dejaba de recordar el autoretrato que el famoso Censor había propuesto a sus lectores antes de empezar a publicar sus discursos ${ }^{50}$ : "en los momentos que me dejan libres los cuidados de la labor de un campo que cultivo cerca de Madrid, leo el Semanario de agricultura, repito algunos de los experimentos que propone, y hago mis cálculos sobre el modo de mejorar este importante ramo. Fui mocito, petimetre, concurrente a la puerta del Sol, a los cafés, teatros, toros y bailes; leía las gacetas extranjeras con el mayor placer. Con mi imaginación llena de fuego fatuo, auxiliaba a unos ejércitos, perseguía a otros, reformaba los gobiernos, y establecía en mi cabeza un mundo, a mi modo, que no había más que pedir. Pero ya, gloria a Dios, caí de mi burra, y veo que todo esto no es más que un embaucamiento de gente ociosa, que desaparece como humo cuando entran los cuidados de una casa, de una familia, y de una labor, y que más beneficio se hace a la sociedad aumentando los frutos de la tierra, que con cuanto papel borra tanto parlador y escribidor como abunda en las cortes ${ }^{\prime \prime 51}$. Como puede notarse el comunicar noticias de interés práctico no impedía cierta presunción literaria.

48. "Carta de un labrador de las inmediaciones de Madrid", in Semanario de Agricultura..., tomo III, $\mathrm{n}^{\circ} 59,15$ de febrero de 1798, pp. 106-108 o pp. 105-106 de nuestra antología.

49. "Carta de un labrador de tierra de Madrid sobre la labor de mulas comparada con la de bueyes", in Semanario de Agricultura...", tomo IV, $n^{\circ} 88,6$ de septiembre de 1798, pp. 145 146: "Me gustó mucho lo que Vms. dijeron acerca de las mulas en el número 74; y a la verdad que ya había tiempo que yo tenía ganas de despotricar contra estos animales que no se reproducen porque, así Dios me salve como yo estoy opuesto a su esterilidad. $Y$ si fuera eso sólo vaya. Pero por otra parte los tales animalitos nos comen por un pie y es muy conveniente poner esto en claro, y sepamos quien es cada uno. A mi ver es constante que el atraso de nuestra agricultura proviene del excesivo número de estas bestias, y de la predilección que merecen todavía entre nosostros...."

50. El Censor. Obra periódica. Tomo primero que contiene la Dedicatoria, y los veinte y tres primeros Discursos publicados en el año de 1781. Madrid 1781, Discurso I, pp. 17-28. Existe una edición facsimil con prólogo y estudio de josé Miguel Caso González. Oviedo 1989, pp. 14-16. También puede utilizarse El Censor (1781-1787) Antología, prólogo de josé F. Montesinos; edición de Elsa García Pandavenes. Barcelona 1972, pp. 61-66.

51. "Carta de un labrador de tierra de Madrid sobre la labor de mulas comparada con la de bueyes", in Semanario de Agricultura..., tomo IV, $\mathrm{n}^{\circ} 88,6$ de septiembre de 1798, p. 145. 
Si exceptuamos el caso de un cultivador aragonés que en 1797 remitió un artículo relativo a la inoculación de las viruelas ${ }^{52}$, todos nuestros labradores, propietarios o agrónomos abarcaron en sus escritos temáticas en relación directa con el mundo agrario. Ahora bien sus intervenciones no obedecían a un esquema único. Algunos, como por ejemplo un hacendado navarro, cuya carta figuraba en el número 22, comunicó a los redactores varias propuestas susceptibles de completar y mejorar su acción. Así les invitaba a describir "sucintamente las plantas y frutales de que hablaren, pues aunque en unas partes sean conocidas, en otras no lo son absolutamente, y los labradores no manejan diccionarios" ${ }^{\prime 53}$. A la par, insistía en la necesidad de proceder a la distribución, en cada provincia, de simientes de las plantas que se deseaba dar a conocer, de comisionar especialistas agrarios y obreros que supieran ejecutar las nuevas técnicas difundidas por el periódico y de ofrecer premios a los labradores que las practicasen con éxito. Según él, los redactores no podían limitarse pues a proporcionar conocimientos sino que también debían tomar medidas concretas para favorecer o simplemente posibilitar su utilización. Antonio Torres Amat, agricultor de Cataluña, al mismo tiempo que dio su parecer sobre el periódico y sobre el papel que habían de cumplir tanto los párrocos como los propietarios acomodados en cuanto a su difusión ${ }^{54}$, aprovechó la ocasión que se le daba de expresarse para comentar un artículo anterior referente al modo de preservar el trigo del tizón y presentar el método que él practicaba y le parecía ser más eficaz ${ }^{55}$. Otros, como Manuel Moreno, cultivador de Torrubia del Campo, informaron a los redactores sobre los progresos que habían realizado gracias a la lectura del Semanario de Agricultura y Artes... Así expuso en

52. "Medicina doméstica", in Semanario de Agricultura..., tomo II, $n^{\circ} 46,16$ de noviembre de 1797, pp. 305-306.

53. "Carta de un hacendado de Navarra", in Semanario de Agricultura..., tomo I, $\mathbf{n}^{\circ} 22,1$ de junio de 1797, pp. 346.

54. "Extracto de carta de un agricultor de Cataluña - Sallent, 30 de julio de 1797", in Semanario de Agricultura..., tomo II, $\mathrm{n}^{\circ} 41,12$ de octubre de 1797, p. 228: "Señores Editores: leo con gran gusto los Semanarios, y veo que si continúan como han comenzado, formarán un cuerpo completo de agricultura y artes. Los párrocos juntarán al pasto espiritual la más útil de las instrucciones, y no quedará su trabajo sin recompensa, si son constantes en combatir los errores inveterados, y en explicar los medios de adelantar. Mucho aprovecharía para esto el que se tuviesen en los pueblos algunos conocimientos de historia natural y botánica, pues con ellos se podrían perfeccionar los ensayos y descubrimientos, bien que preveo que el Semanario hará despertar el gusto a estos estudios que ya conozco no son para el común de los labradores, sino para propietarios acomodados, que al mismo tiempo que aumenten sus intereses, den a conocer con sus experimentos nuevos ramos de riqueza, y tengan una ocupación noble y lucrativa, huyendo la vergonzoza ociosidad en que muchos viven."

55. "Extracto de carta de un agricultor de Cataluña...": "En el núm. 2 leí los medios de precaver el trigo del tizón, y siendo yo uno de los labradores que han practicado con buen éxito muchos años ha el método que Vms. recomiendan, el cual ya usaba mi bisabuelo, muy amante de la agricultura, me ha servido de la mayor complacencia el verlo recomendado. Ahora practico otro que es el siguiente..." 
su carta cómo había logrado sacar provecho de una heredad hasta entonces improductiva, cultivando el chamorro blanco cuya primera cosecha le había proporcionado un beneficio neto de 1554 reales $^{56}$. Algunos solicitaron informaciones concretas con el fin de potenciar su propia actividad. Entre ellos, un azucarero limeño que, en nombre suyo y en el de su corporación, declaraba al referirse al modo de refinar el azucar: "No sabemos los autores que tratan de esta materia, ni aquí vienen estos libros, ni tenemos noticia de lo que modernamente se hace en las refinadurías; por eso hago presente la necesidad que tenemos de noticias sobre el mejor cultivo de la caña, uso de lejías, clarificaciones de melado y operaciones más fáciles y practicables en estas haciendas..." ${ }^{157}$ Otros, finalmente, dieron a conocer sus trabajos o los de instituciones cuyos objetivos coincidian con los del periódico. Tal fue el caso de Serapio Sinues, catedrático de agricultura y miembro de la Real Sociedad Aragonesa de Amigos del País. Como tal participó en 1779 en la creación de una escuela pública de agricultura y economía rural cuyo histórico proporcionó a los editores con la esperanza de que su publicación incitaría las demás sociedades a seguir tan loable iniciativa ${ }^{58}$. Pero el ejemplo más relevante quizás sea el de los hermanos Claudio y Estebán Boutelou, insignes botánicos y jardineros de S.M. en Aranjuez, que, al poco tiempo de ser creado el periódico (en agosto de 1797) entablaron una correspondencia seguida con los editores remitiéndoles varias cartas o artículos sobre temas variados ${ }^{59}$. Semejante interés por la obra no podía pasar desapercibido y éste fue pagado con creces ya que en 1805, cuando se produjo el cambio dirreccional, los Boutelou pasaron de meros corresponsales a redactores permanentes ${ }^{60}$.

56. "Carta de un cultivador de la Mancha, sobre el producto de una corta heredad", in Semanario de Agricultura...", tomo XVII, $n^{\circ}$ 440, 6 de junio de 1805, pp. 367-368.

57. "De los medios de mejorar en Lima la fabricación del azucar. Carta de un hacendado de Lima", in Semanario de Agricultura...", tomo XVI, n 392, 5 de julio de 1804, p. 11.

58. "Del Establecimiento y progresos de la Cátedra de Agricultura de Zaragoza. Por Serapio Sinúes, Zaragoza, 6 de junio de 1797", in Semanario de Agricultura..., tomo 2, $n^{\circ} 32,10$ de agosto de 1797, pp. 78-82. [p. 82: "Este es el compendio de la historia que en brevísimo tiempo he formado de mi cátedra de agricultura por mí mismo, pues mi compañero se halla ausente convaleciendo de una gravísima enfermedad. El mayor mérito en mi concepto de este utilísimo establecimiento consiste en la sencillez con que se ha ido organizando y acaso a esto mismo se deben los grandes progresos que se han hecho por sus discípulos especialmente en estos últimos años. Si para mover a otras sociedades de la península a seguir su ejemplo, o para algún otro fin igualmente conveniente, juzgasen Vms. del caso la publicación de esta breve noticia en el semanario de agricultura, podrán Vms. hacerlo, en la inteligencia de que en ello recibirá singular complacencia este cuerpo patriótico."

59. Vease la introducción de nuestra antología, pp. 31-32.

60. Si bien Claudio Boutelou formaba parte oficialmente del nuevo equipo junto a Francisco Antonio de Zea y Simón de Rojas y Clemente, la participación de Estebán Boutelou (que no era miembro del Real Jardín Botánico de Madrid) fue admitida "en atención a los servicios distinguidos que ha hecho a la empresa, a la Agricultura, y al Jardín." Véase la introducción de nuestra antología, p. 27. 
Junto a este primer colectivo que respondió al llamamiento de los responsables del periódico, figuraban también 5 albéitares a los que podemos agregar 2 mariscales que colaboraron más en calidad de veterinarios que de militares. Asimismo, uno de ellos aceptó con entusiasmo la oportunidad que se le ofrecía de participar en una obra divulgativa dirigida a sacudir, según sus propios términos, "Ios errores y extravíos admitidos en la práctica del arte que más contribuye a nuestra felicidad" ${ }^{\prime 61}$. Impulsado por su afán de contribuir al desarrollo de su arte y como lector asiduo del periódico, firmó en 1797, bajo el seudónimo de EI Mariscal, cinco artículos referentes sea a la cría de caballos, sea a las enfermedades de los bueyes ${ }^{62}$. Sensible a la voluntad de los editores de conferir a la obra un carácter interactivo, basado en el diálogo entre amantes de la patria, puso a disposición de aquellos tanto sus conocimientos como sus dotes de observación y su curiosidad intelectual para favorecer la concreción de los proyectos presentados en el Semanario de Agricultura y Artes... Así, tras leer en el número 36 (con fecha del 7 de septiembre de 1797) la carta del cura de Bernui de Coca sobre la creación de una escuela de labradores en que parte de la enseñanza se dedicaría a la veterinaría ${ }^{63}$, aprovechó una serie de viajes para interrogar a varios veterinarios o herradores y colectar informaciones que permitiesen elaborar una cartilla conforme a lo preconizado por el eclesiático. El 19 de octubre del mismo año, el fruto de sus indagaciones daba lugar a un nutrido artículo en el Semanario $^{64}$. Obviamente, el celo de El Mariscal debió de satisfacer por completo tanto a los redactores como a Juan Tellez, vecino de Tordehumos (villa de 1075 habitantes de la provincia de Valladolid ${ }^{65}$ ), que, por carta del 14 de febrero de

61. "Señores Editores del Semanario de Agricultura", in Semanario de Agricultura..., tomo I, $n^{\circ} 20,18$ de junio de 1797, p. 15: "La variedad apreciable e instructiva que contiene el nuevo periódico dirigido a que sacudamos los errores y extravíos admitidos en la práctica del arte que más contribuye a nuestra felicidad, me mueve a dirigir a Vms. la presente, y si en su contenido encuentran alguna cosa digna de publicarse, espero la inserten Vms. en él."

62. "Carta a los Editores del Semanario - Veterinaria", in Semanario de Agricultura..., tomo I, $n^{\circ} 13,30$ de marzo de 1797, pp. 198-203; $n^{\circ} 14,6$ de abril de 1797, pp. 215-218 y $n^{\circ} 20$, 18 de junio de 1797, pp. 230-231; "Carta sobre las enfermedades de los bueyes", in id., tomo II, $n^{\circ} 42,19$ de octubre de 1797, pp. 239-241 y n 43, 26 de octubre de 1797, pp. 255-260.

63. "Carta de un párroco del obispado de Segovia", in Semanario de Agricultura..., tomo II, $n^{\circ} 36,7$ de septiembre de 1797, pp. 139-148 o pp. 95-104 de nuestra antología.

64. "Carta sobre las enfermedades de bueyes", tomo II, $\mathrm{n}^{\circ} 42,19$ de octubre de 1797, $p$. 239: "Señores Editores: deseando contribuir a la formación de la cartilla de veterinaria que se indica en el artículo XXII de la escuela de agricultura, erigida en Bernui de Coca bajo la dirección de un cura párroco, paso a manos de Vms. las observaciones que sobre las enfermedades de los bueyes me han comunicado diferentes maestros de albéitar y herrador de los pueblos del partido de Avila y Segovia, por los que de orden superior he viajado. Si la casualidad me ha proporcionado ver el buey o vaca enferma, lo he hecho; y el resultado de lo que he observado lo añado en nota. Igualmente añado bajo la misma forma lo que me respondieron algunos maestros al preguntarles sobre las enfermedades observadas en el ganado vacuno por el señor Ratael Moyano, maestro de herrador y albéitar en San Vicente de Palacio, quien me las comunicó en carta de 17 de mayo de 1797 y copiadas son las siguientes..."

65. Cf. Censo de Floridablanca. Madrid 1787. 
1797, había llamado la atención de los publicistas sobre la necesidad imperiosa de proporcionar a los campesinos nociones de veterinaria y de contribuir al desarrollo de ese arte ${ }^{66}$. La reacción de los editores fue inmediata. En su respuesta, publicada a continuación, manifestaron su voluntad de corresponder a tan atinada exigencia y, cumpliendo con lo pedido, insertaron en su escrito dos cartas relativas a la viruela del ganado lanar, la primera firmada por Joseph Enciso, mariscal mayor del Regimiento de Caballería de Voluntarios de España, la segunda por un díscipulo del albéitar de Torrelaguna (villa de 1812 vecinos, en la provincia de Toledo $\left.{ }^{67}\right)^{68}$. Una vez más se daba prioridad al diálogo con el público, al género epistolar, lo que permitió a menudo provocar la participación de lectores que, de no ser así, quizás no se hubieran atrevido a comunicar sus observaciones a los redactores. Tal fue el caso de Isidro Lozano, maestro albéitar de la villa de Sadava en Aragón (1211 almas) ${ }^{69}$, que, movido por el ejemplo de colegas suyos, decidió remitir al periódico un texto sobre el muermo ${ }^{70}$.

Los redactores hallaron también interlocutores directos en el mundo de la medicina representado por 3 cirujanos, 2 médicos, 1 boticario y 1 profesor de farmacia. El último, Joseph Antonio Mañas, que ejercía en Ejea de los Caballeros, fue el único en no tocar un tema directamente relacionado con su especialidad. Sin embargo, intervino como científico, para confirmar (con el respaldo de reiteradas experiencias) la validez del método presentado en el número 39 para extraer aceite de la uva o del orujo ${ }^{71}$. Juan Antonio Requena,

66. "Carta a los Editores", in Semanario de Agricultura..., tomo I, $n^{\circ} 15,13$ de abril de 1797, p. 231: "Como la Veterinaria está hoy en nuestra península con tan pocos progresos, y se abunda tanto en esta tierra de campos de ganado de todas especies, teniendo al mismo tiempo muchos pueblos la imposibilidad de mantener un maestro albéitar, he de deber a Vms. que toquen cuanto puedan esta materia, pues harán un crecido servicio al público, y en especial a los labradores que quedan muchas veces perdidos y abandonados a la miseria por falta de alguna caballería de labranza que acaso fenece por la impericia de los veterinarios..."

67. Cf. Censo de Floridablanca. Madrid 1787.

68. "Respuesta", in Semanario de Agricultura..., tomo I, $\mathrm{n}^{\circ} 15,13$ de abril de 1797, pp. 231-233. [p. 232: “En cuanto a la Veterinaria daremos al señor Tellez, y principalmente al público una prueba de que nuestros deseos son los mismos que expresa la carta, publicando la siguiente receta que nos ha comunicado Don Joseph Enciso...."; p. 233: "También publicaremos la siguiente carta que contiene un remedio para la sarna y roña del ganado lanar, pues además de ser su composición bastante simple y poco costosa, tiene la ventaja de no perjudicar a las lanas...."]

69. Cf. Censo de Floridablanca. Madrid 1787.

70. "Extracto de una carta de Don Isidro Lozano, maestro albéitar en la villa de Sadava en Aragón, sobre el muermo", in Semanario de Agricultura..., tomo IX, $\mathrm{n}^{\circ} 228,14$ de mayo de 1801, pp. 301-307: "he visto que algunos veterinarios publican en el semanario sus métodos de curar la viruela de ganado lanar; y deseando yo contribuir al bien público, he de hacer presente a Vms. que padecen igual enfermedad los caballos, mulos..."

71. Carta de Joseph Antonio Mañas, profesor de farmacia en Ejea de los Caballeros, 16 de noviembre de 1797, in Semanario de Agricultura..., tomo III, $\mathrm{n}^{\circ} 53,4$ de enero de 1798, pp. 8-14. 
cirujano de aldea que residía en Revilla del Campo (lugar de 451 vecinos de la provincia de Burgos ${ }^{72}$ ), también obró como garante de las informaciones difundidas por el periódico. Así, señaló que siguiendo las instrucciones de los redactores había inoculado la viruela con éxito a cuatro niños ${ }^{73}$. Su homólogo de Villalba ${ }^{74}$, Francisco Xavier Echaide, respondió a la demanda informativa de los periodistas. Efectivamente, fue a raíz de una nota inserta en el número 14, referente a los terribles resfríados que en marzo de 1797 habían enlutado la capital $^{75}$, que mandó una carta sobre el modo de atajar tales epidemias ${ }^{76}$. Los redactores sin embargo no juzgaron oportuno publicarla de inmediato y habrá que esperar fines de 1799 para que, al escasear la correspondencia recibida, la extraigan de sus archivos. Mucho más atractiva les pareció la respuesta del médico Juan Antonio Pasqual y Rubio que practicaba en Belmonte de la Mancha $^{77}$. A diferencia de Francisco Xavier Echaide, éste no se limitó en dar cuenta de los remedios que había utilizado para contener una epidemia similar que había afectado su comarca. Inició su carta con un largo párrafo introductorio en el que puso de realce la suma utilidad del periódico así como sus propios esfuerzos para contribuir a su difusión. "Yo leo-decía- cuanto puedo de bueno que se publica, y si he de hablar con la ingenuidad que es propia a todo hombre de bien, y lo poco que mi cortedad alcanza, confieso que en cuantos periódicos han salido a luz, ninguno tan útil como el Semanario de agricultura, y más si fuera posible quitar la preocupación y envejecidos errores de la mayor parte de nuestras gentes, que confío que el tiempo y la eficacia y celo de nuestros buenos patriotas enmienden. Yo en esta villa, que es una de las principales del obispado de Cuenca, procuro extender y evidenciar la utilidad del Semanario" ${ }^{\prime 78}$. A modo de ejemplo exponía a continuación cómo, siguiendo las sabias recomendaciones de los redactores y en beneficio de la colectividad, había favorecido la introducción del cultivo de las patatas, la fabricación del

72. Cf. Censo de Floridablanca. Madrid 1787.

73. "Inoculación" (Carta de Juan Antonio Requena, 26 de febrero de 1798), in Semanario de Agricultura..., tomo $V, \mathrm{n}^{\circ} 112,21$ de febrero de 1799, p. 128.

74. Los datos que poseemos no nos han permitido determinar la procedencia geográfica de Francisco Xavier Echaide ya que en el Censo de Floridablanca figuran 21 localidades con el nombre de Villalba.

75. "En el mes de Marzo último se manifestaron en Madrid muchos resfriados con calentura fuerte y tos, que han causado bastantes muertes, degenerando muchas veces en pulmonías. Si la facultad de medicina ha hecho sobre esta epidemia observaciones que puedan servir de regla para el método curativo, y se sirve comunicarlas a este Semanario, se publicarán para que con su conocimiento se eviten en los pueblos, si se propaga la epidemia, los funestos extragos que se han experimentado en esta capital.", in Semanario de Agricultura..., tomo 1, $n^{\circ} 14$, 6 de abril de 1797, p. 224.

76. "Carta de un cirujano de Villalba sobre resfriados", in Semanario de Agricultura..., tomo $V, \mathrm{n}^{\circ} 149,7$ de noviembre de 1799, pp. 303-304.

77. Villa de 2636 habitantes. Cf. Censo de Floridablanca. Madrid 1787.

78. "Carta de Belmonte de la Mancha", in Semanario de Agricultura..., tomo III, n 56, 25 de enero de 1798, p. 62. 
pan de patatas y cómo pensaba experimentar la producción de aceite de orujo y de uva. A la par se comprometía en proceder a ensayos diversos y en dar constancia del resultado de los mismos. Como era de esperar, los periodistas se apresuraron en publicar esa carta que, más allá de su carácter informativo, conllevaba un fuerte cariz publicitario y les permitía por añadidura ofrecer a los lectores el retrato del perfecto hombre de bien que, en calidad de patriota, se interesaba por temas muy diversos, sin relación directa con su actividad personal, y no escatimaba sus esfuerzos para favorecer la difusión de las luces en pro del bien público. Sin embargo la ejemplaridad de nuestro médico tenía sus límites. Si su conducta era digna de aprecio, no cabe la menor duda que sus intenciones no eran del todo desinteresadas. Efectivamente, Juan Antonio Pasqual y Rubio, que a diferencia de otros corresponsales no optó por el anonimato, aprovechó la oportunidad para proceder a un autoretrato de los más favorecedores que, por contraposición, dañaba la imagen de parte de sus homólogos. Así, al referirse a lo acaecido durante la epidemía de resfriados, declaraba: "algunos facultativos se apresuraron a multiplicar remedios, y ser muy oficiosos, sin omitir repetición de sangrías, y se desgraciaron muchos. Yo que en treinta y ocho años de práctica he estudiado y estudio sin cesar, más para no hacer, que para hacer, siguiendo sólo la observación del divino Valles, que dice, más querré caer en manos de un médico ignorante, que se esté parado, que no en la de un oficioso aunque sea sabio, me detuvo en jaropear, y me detengo siempre hasta que la naturaleza me dice lo que tengo que hacer, conociendo cómo se explica, el cuándo, y por dónde, con lo demás indispensable para no errar; pues ya que el médico no alivie, a lo menos no debe dañar..."79.

\section{Un colectivo variopinto que no excluye a las mujeres}

Entre los 56 corresponsales láicos cuya profesión nos es conocida figuraban también 3 alcaldes mayores, 1 administrador de correos, el veedor de una fábrica de curtidos, 1 diplomático, 3 militares, 3 abogados, 1 profesor de química, 2 fabricantes y 1 maestro de lanas. Como subrayó un militar curioso de Sanlucar de Barrameda, en una carta que destacaba por la diversidad y la riqueza de las temáticas abarcadas ${ }^{80}$, el Semanario de Agricultura y Artes... era el lugar

79. "Carta de Belmonte de la Mancha", pp. 62-63.

80. "Carta de un militar curioso de Sanlucar de Barrameda a los Editores del Semanario de agricultura", in Semanario de Agricultura..., tomo IV, $n^{\circ} 82$, pp. 55-61 (o 117-123 de nuestra antología) y "Concluye la carta del militar curioso de Sanlucar de Barrameda" , n 83, 2 de agosto de 1798, p.74-80. "He visto [escribía a modo de introducción] con placer algunos de vuestros Semanarios y, desde luego, me suscribo a los panegiristas de un periódico que promete felicidades a la nación. Desde que nuestro primer padre por un eterno decreto fue obligado a desentrañar la tierra para comer el pan mezclado con el sudor de su rostro, todos hemos nacido labradores por herencia. Por tanto, no será extraño que un discípulo de Marte preste atenciones a Ceres, sin cuyo auxilio no puede aquél dar un paso. Ved aquí algunas especies sueltas que la curiosidad me suministra, capaces tal vez de contribuir al plan que os habeis propues- 
"donde cada Español puede presentar liberalmente la muestra de sus observaciones para el beneficio común" ${ }^{\prime \prime}$. Esto sin excluir a las mujeres que también habían de participar en la difusión de las Luces. Convencidos de ello y deseosos de suscitar igualmente el interés del público femenino ${ }^{82}$, los editores dieron cabida a los escritos de cuatro representantes del bello sexo. Su participación puede parecer anecdótica, por lo menos a nivel cuantitativo: fueron 4 artículos que sumaban en total 34 páginas. Sin embargo, la mera presencia de cartas firmadas por mujeres es de por sí excepcional, cuanto más habida cuenta el carácter especializado de la obra. La primera en aportar su contribución a los redactores fue doña María Cuenca, esposa del ministro plenipotenciario de Carlos IV en la Haya. En su carta, que cerraba el número 25 (con fecha del 22 de junio de 1797$)^{83}$, dio cuenta de las observaciones que había podido hacer viajando por Suecia, país cuya prosperidad tan sólo podía suscitar la admiración y cuyos usos eran dignos de imitación. Así describió cómo el monarca de esa nación, "convencido de que sin labradores y gentes industriosas mejoraría poco el estar de sus súbditos", había logrado introducir "entre toda clase de gente el amor al campo" hasta convertir cortesanos improductivos en hombres capaces, por su labor, de contribuir al fomento económico del país ${ }^{84}$. A la par llamó la atención de los editores sobre el excelente arreglo de los caminos, la eficacia de los transportes, la importancia concedida al plantío de árboles, la sencillez y el apego al trabajo de unos hombres que no se dejaban cegar por el lujo y la aparencia. Compadecida ante "el letargo e indolencia" de sus compatriotas, carácteristicas que contrastaban sobremanera con el dinamismo de los

to." (p. 55). A continuación venían diversas observaciones sobre temas muy variados como lo demuestran los títulos de los distintos apartados que constituían su escrito: Ejemplo de emulación, Regadíos, Economía doméstica, Fecundidad de las semillas, Medicina doméstica, Duda Teológico moral, Celo parroquial, Recreación vulgar, Veterinaria, Socorro de la agricultura en los pueblos más pequeños y Reflexiones. Rehuyendo de cualquier protagonismo, prefirió no revelar su identidad y concluía: "Esto es, sabios Editores, lo que por ahora me ocurre que deciros. Por falta de método, estilo y corrección, conoceréis que no me he tomado este trabajo para lucir, y sí sólo por si puedo servir de algún provecho a nuestros hermanos. Perdonad, os suplico, la molestia que os cause la lectura de este borrador bosquejado de prisa, y creed que soy vuestro más apasionado servidor".

81. "Concluye la carta del militar curioso de Sanlucar de Barrameda", n 82, p. 56 (o p. 118 de nuestra antología).

82. Sobre el público feminino de la prensa véase in LARRIBA, Elisabel, Le Public de la presse en Espagne à la fin du XVIIIe siècle (1781-1808), el capítulo III de la segunda parte, pp. 149178: "L'inégalité des sexes. Les abonnées aux périodiques: une élite intellectuelle ou une élite sociale?".

83. "Extracto de carta de una señora Española, cuyas observaciones en Suecia, y en su viaje desde aquel país al Haya, nos han parecido dignas de publicarse", in Semanario de Agricultura..., tomo I, $\mathrm{n}^{\circ} 25,22$ de junio de 1797, pp. 396-400. [La identidad y la calidad de la autora de la referida carta aparecen en nota, p. 396.$]$

84. "Extracto de carta de una señora Española, cuyas observaciones en Suecia, y en su viaje desde aquel país al Haya, nos han parecido dignas de publicarse", p. 397. 
suecos ${ }^{85}$, y anhelante de cambio, ${ }^{86}$ declaraba con cierta amargura: "muchas cosas hay en la Suecia que he visto con envidia que no existen en mi propio país: v. g. no se ve un pobre, ni sé que haya hospicios. Todo el mundo trabaja en el campo o en fábricas, y el más infeliz tiene su casita con más comodidad y aseo que las gentes de convenencias en nuestros pueblos. [...] En considerando la fertilidad de mi amada patria, y volviendo los ojos a la esterilidad de estos países, en que sin embargo disfrutan sus habitadores de tantos bienes, me causa el mayor sentimiento. Quisiera me fuese posible transplantar toda la industria, la sobriedad y la moderación en el vestir a nuestro país" ${ }^{\prime \prime 7}$. Los redactores, que aspiraban a dar a conocer cuanto en el extranjero podía ser fuente de progreso, aceptaron gustosos el testimonio de esa insigne dama $y$, sensibles a su celo patriótico, no dudaron en presentarla como un ejemplo para cuantos residieran fuera de la Península ${ }^{88}$. Al igual que María Cuenca, Matilde G. Sendín, que había recibido una instrucción pulida y pertenecía a una élite tanto social como intelectual, no despreció los aportes de las demás naciones. Así, bajo la dirección de su profesor de francés, que aborrecía "de muerte las novelas, comedias, historias y cuentos" ${ }^{\prime 89}$, se había formado en el arte de la traducción y se había dedicado a la lectura de obras que no solían figurar en la biblioteca de una mujer. Con lo cual, remitió a los editores, en calidad de traductora, la versión española de un estudio referente a la fabricación del salitre firmado por Chaptal y sacado del Journal des Arts et Manufactures ${ }^{90}$, prometiéndoles pasar en breve al castellano un tratado sobre hilazas que podría interesarles. Muy diferentes fueron las participaciones de F.B. y María Morales. La

85. Véase al respecto el artículo "Suède" del Dictionnaire géographique portatif, ou description des Royaumes, Provinces, Villes, Patriarchats, Evêchés, Duchés, Comtés, Marquisats, Villes impériales et hanséatiques, Ports, Forteresses, Citadelles et autres Lieux considerables des quatre parties du Monde (...) Traduit de l'Anglois, sur la treisième édition de Laurent Echard, par Mr. Vosgien, Chanoine de Vaucouleurs. Nouvelle Edition, augmentée de la Géographie ancienne, \& de plus de 700 articles de la Géographie moderne; ainsi que corrigée \& augmentée dans un grand nombre d'autres, tomo second. Bruxelles 1783, en que se puede leer (tomo II, p. 361-a): "Les Suédois sont robustes, très laborieux, propres aux choses sérieuses, \& à endurer la fatigue."

86. "Extracto de carta de una señora Española...", p. 399: "Cuando éstos salgan de su letargo e indolencia, lo mismo y más se verá en España que en el país más floreciente que se conozca."

87. "Extracto de carta de una señora Española...", p. 398-399.

88. "Nota", in tomo I, $n^{\circ} 25,22$ de junio de 1797, p. 400: "Muy apreciable sería que los nacionales dispersos en los varios países extranjeros dedicaran su atención a apurar cuanto puede conducir a la felicidad de sus consúbditos, inflamados de un celo plausible como el que distingue a la Señora que ha dirigido a los Editores la carta que precede."

89. "Señores Editores del Semanario de Agricultura", in Semanario de Agricultura..., tomo IX, $n^{\circ} 222,2$ de abril de 1801, p. 223.

90. La traducción de las "Observaciones sobre la fabricación del salitre, y establecimientos artificiales, por J.A. Chaptal" fue publicada in Semanario de Agricultura..., tomo IX, $n^{\circ} 222$ (2 de abril de 1801), pp. 223-232, $n^{\circ} 224$ (16 de abril de 1801), pp. 240-248 y n 225 (23 de abril de 1801), pp. 255-261. 
primera, una señora conocida cuya identidad no fue revelada, se limitó a relatar con harta concisión cómo, recurriendo a remedios caseros, de los que hasta entonces desconfiaba, había logrado recuperar la salud cuando los médicos lo habían dado por imposible ${ }^{91}$. La segunda, mujer de condición modesta que residía en Lucillos (lugar de 574 habitantes en la provincia de Toledo ${ }^{92}$ ), sin ser lectora del periódico (lo cual demuestra que el intento de confiar a los curas párrocos el papel de intermediario cultural no era nada descalabrado) sabía de oídas que los editores habían recomendado el uso de la polenta por ser ésta nutritiva y. de coste reducido. Siguiendo el ejemplo de los redactores y por mediación suya, había determinado dar a conocer un guiso a base de gachas de almortas, poco costoso, sabroso y de gran alimento que, por ello, "sería de mucha utilidad para los pobres" ${ }^{\prime 93}$. Con lo cual, tras presentar las almortas, cultivadas en contadas regiones, expuso con amenidad y precisión las diferentes maneras de guisarlas y utilizarlas. Asimismo, a sabiendas de lo difícil que resultaba vencer tanto la ignorancia como el recelo que solía provocar cualquier forma de novedad ${ }^{94}$, no omitió proporcionar en su carta ejemplos concretos que pusieran de realce el provecho que podía sacarse de tal planta ${ }^{95}$.

Al ceder la palabra a cuatro mujeres de perfil tan divergente (social y culturalmente), los redactores demostraban una vez más y de manera fehaciente su

91. "Remedio para los flujos de sangre y para el dolor de oídos - Carta de una señora conocida", in Semanario de Agricultura..., tomo XIV, n 340, 7 de julio de 1803, p. 16: "Desde estas dos ocasiones tengo más fe en los remedios caseros que en todas las recetas. Nadie lo despreciará tanto como yo lo hice, hasta que vi el efecto, en que seguramente no me puedo equivocar."

92. Cf. Censo de Floridablanca. Madrid 1787.

93. "Carta de una Sra. de Lucillos sobre el uso de las gachas", in Semanario de Agricultura..., tomo III, n 77, 21 de junio de 1798, p. 399.

94. "Carta de una Sra. de Lucillos sobre el uso de las gachas": "Me parece que oigo decir a muchos: yo no como las gachas o puches de harina de trigo, con qué miren ¿cómo comeré ese alimento tan grosero? Digo que es trabajo el introducir un alimento de nuevo. Aunque sea mejor, al punto damos sentencia de que eso no puede estar bueno, sin más razón que porque yo no lo he comido. ¡O y cuántas hambres se padecerían menos si nos desimpresionáramos de estas ideas tan erradas!"

95. "Carta de una Sra. de Lucillos sobre el uso de las gachas", p. 400: "Así hecho este guisado es de tanto alimento, que hombres del campo que lo comen por la mañana aseguran que se sienten más alimentados que con un puchero o con migas. Con media fanega de almortas que se hagan harina, que en un año regular vale $15 \mathrm{rs}$. tiene un pobre para dar por espacio de cuatro meses una comida diaria a su familia, aunque tenga tres o cuatro hijos. ¡Qué lástima que no nos valgamos de este arbitrio en unos tiempos como los presentes! ¡O pereza española los males que acarreas!

También se hacen dichas gachas con harina de pitos o titos que son unos guisantes pequeños que se siembran como las almortas o a monta, o a liños en tierras de secano, y que se han de sembrar al año siguiente de trigo. En tierra de Madrid los labradores hacen dicha harina, $y$ en el invierno la venden a cinco o seis cuartos la libra, y a veces más barata, y es un socorro bellísimo para los pobres. Algunos pobres arrieros cuando van de camino llevan su saquito de harina cernida, y su especia de pobre molida, y con facilidad tienen que comer aunque lleguen a un pueblo desprevenido, como sucede frecuentemente." 
voluntad de interesar e implicar a un público variopinto, en el que las diferencias de sexo y de estatus se difuminaban ante el protagonismo del hombre de bien, lato sensu, que, guiado por el interés hacia la causa pública y la voluntad de ser útil, merecía todos los honores.

\section{Distribución geográfica de los corresponsales}

Ahora bien, los datos proporcionados por las cartas publicadas en el Semanario de Agricultura y Artes... nos permiten determinar no sólo el perfil socio-cultural de sus autores sino también, en la mayoría de los casos, su procedencia geográfica. Efectivamente la localidad en que residían viene indicada para 137 de ellos (o sea el $73,7 \%$ ) y para otros 17 (o sea el $9,1 \%$ ) se hace mención al menos de la provincia o región a que pertenecían. En ciertas ocasiones incluso, la identidad del remitente del escrito se desvanece en beneficio de un personaje arquetípico definido por su calidad y / o tan sólo por su ubicación geográfica. Se trataba para los redactores, mediante el recurso a un título a veces elíptico que ponía de realce una región sin evocar sistemáticamente el tema desarrollado, de suscitar o incrementar el interés de los lectores procedentes de la misma con el aliciente de noticias en relación directa con su entorno, es decir de informaciones de carácter utilitario y plenamente adaptadas a su realidad cotidiana. Con lo cual, y entre otros ejemplos, publicaron, en junio de 1797, la ya citada Carta de un hacendado de Navarra ${ }^{96}$. En el número 48 , de noviembre del mismo año, se podía leer un texto sobre los olivos herbequines (los únicos capaces, según el autor, de resistir al frío del norte de España) titulado Un párroco del obispado de Solsona dice a los Editores y encabezado por la siguiente nota: "Esta observación la escribe un párroco catalán del obispado de Solsona que, como nada pretende sino el bien público, su nombre calla" ${ }^{\prime \prime 7}$. En 1804, dieron cabida a la Carta de un párroco de Aragón sobre los medios de fomentar algunos artículos de economía rural ${ }^{98}$ y en abril de 1805 a la de un "extremeño sobre el mejor aprovechamiento de algunos terrenos de aquella provincia" ${ }^{\prime \prime 9}$. Así, a través la correspondencia reproducida en el periódico, los redactores ofrecían a sus lectores un amplio recorrido por la Península mediante el cual demostraban que se interesaban por toda España y que por tanto eran capaces de interesar a toda España. Su ánimo desde luego siempre había sido conferir a la obra una difusión de carácter nacional sin excluir ni siquiera a los territorios de ultramar. Con esa finalidad habían multiplicado,

96. "Carta de un hacendado de Navarra", in Semanario de Agricultura..., tomo I, $n^{\circ} 22,1$ de junio de 1797, p. 346.

97. "Un párroco de Solsona dice a los Editores...", in Semanario de Agricultura..., n48, 30 de noviembre de 1797, p. 340.

98. Semanario de Agricultura..., tomo XV, $\mathrm{n}^{\circ} 377,22$ de marzo de 1804, p. 177-180.

99. "Carta de un extremeño sobre el mejor aprovechamiento de algunos terrenos de aqueIla provincia", in Semanario de Agricultura..., tomo XVII, $\mathrm{n}^{\circ} 432,11$ de abril de 1805, pp. 225227. 
desde el principio, los puestos de venta ya que los pedidos podían efectuarse en Madrid (en la librería del Castillo, frente a San Felipe) pero también "en todas las capitales de las Diócesis de España y sus Indias" y, lo cual era un hecho único, en "los Hospicios, Hospitales, Casas de Expósitos o de Corrección quedando a favor de ellas un 7 por ciento del producto"100. Obviamente, los publicistas, que no carecían de ambición, estaban determinados a conquistar y fidelizar un público polifacético tanto a nivel socio-profesional como geográfico y para ello contaban con el apoyo de una extensa red de colaboradores que cubriera la totalidad de la Península. Así en el Diálogo entre D.C. y D.A. sobre el modo más conveniente de publicar el Semanario de agricultura para que sea útil ${ }^{101}$ equiparaban la obra del periódico a la de un "Consejo que respondiese a las dudas y dificultades que ocurriesen a los pueblos y particulares en la ejecución de las prácticas que se indicasen sobre agricultura, economía doméstica, industria, cría de ganados [...] y tuviese sus corresponsales en todas las provincias del reino para consultarles y llevar a unas los conocimientos de otras"102. Sin embargo los resultados obtenidos no siempre estuvieron a la altura de las esperanzas de los editores como lo demuestra el cuadro que viene a continuación.

Distribución de los corresponsales por intendencias ${ }^{103}$

\begin{tabular}{|lc|lc|}
\hline \multicolumn{1}{|c|}{ Intendencia $\mathrm{y}^{\circ}{ }^{\circ}$ de corresponsales } & \multicolumn{2}{|c|}{ Intendencia y $\mathrm{n}^{\circ}$ de corresponsales } \\
\hline Aragón & 21 & Asturias & 2 \\
\hline Toledo & 12 & Cuenca & 2 \\
\hline Extremadura & 11 & Guadalajara & 2 \\
\hline Sevilla & 10 & Murcia & 2 \\
\hline Soria & 10 & Navarra & 2 \\
\hline Burgos & 9 & Segovia & 1 \\
\hline Cataluña & 9 & Avila & 1 \\
\hline Granada & 7 & Nuevas Poblaciones & 1 \\
\hline La Mancha & 6 & Palencia & 1 \\
\hline León & 6 & Toro & 1 \\
\hline Galicia & 5 & Viscaya & 2 \\
\hline Madrid & 5 & Extranjero y territorios de ultramar \\
\hline Salamanca & Suecia (La Haya) & 2 \\
\hline Valladolid & 5 & América (Lima + Guatemala) & \\
\hline Guipúzcoa & 5 & & 152 \\
\hline Reales Sitios & 4 & Total & \\
\hline Valencia & 3 & & \\
\hline
\end{tabular}

100. "Prospecto", in Semanario de Agricultura..., tomo I, 1797, p. XV (o p. 80 de nuestra antología).

101. "Diálogo entre D.C. y D.A. sobre el modo más conveniente de publicar el Semanario de Agricultura y Artes para que sea útil", in Semanario de Agricultura..., tomo VII, n 165, 27 de febrero de 1800, pp. 139-144 (o pp. 133-139 de nuestra antología).

102. "Diálogo entre D.C. y D.A. sobre el modo más conveniente de publicar el Semanario de Agricultura y Artes para que sea útil", p.143 (o p. 137 de nuestra antología). 
Los redactores podían vanagloriarse de disponer de corresponsales en 28 intendencias a los que cabe agregar 4 españoles que residían fuera de la Península, sea en el extranjero, sea en los territorios de ultramar: María Cuenca, esposa del ministro plenipotenciario de S.M. en La Haya, Manuel Josef Ruiz de Olalla, secretario de la legación española en la misma ciudad, así como un hacendado limeño y un vecino de Guatemala cuya identidad no fue revelada. Sin embargo la distribución geográfica de ese colectivo distaba mucho de ser homogénea. Cuando el periódico contaba en varias provincias con un escaso número de colaboradores, algunas regiones destacaban, comparativamente, por su fuerte receptividad. Así, el 13,8\% del corpus (21 individuos) procedía del reino de Aragón que (tal como Extremadura que ocupa también una posición señalada en nuestra clasificación) se caracterizaba por una población de tipo rural (la principal destinataria de la obra), una industria primitiva, un comercio rudimentario y una agricultura arcáica obstaculizada a la par por condiciones naturales mediocres. Esos resultados no son nada sorprendentes ya que, según la lista de abonados publicada en $1806^{104}$, los principales núcleos de difusión del periódico eran precisamente Aragón y Extremadura que concentraban, respectivamente, el $13,3 \%$ y el $24,2 \%$ de los suscriptores (o sea 46 y 84 individuos) $)^{105}$. Los redactores hallaron igualmente un apoyo valioso en Andalucía que totalizaba 19 corresponsales (el $12,5 \%$ del corpus) y presentaba un perfil totalmente opuesto. Debido a su riqueza económica y cultural, a su fuerte índice de urbanización, ofrecía (a diferencia de las dos provincias citadas anteriormente) un terreno propicio a la difusión de la prensa y llegó a ser, incluso, el principal centro de lectura periodística después de Madrid, por supuesto ${ }^{106}$.

Si algunas regiones produjeron un número apreciable de corresponsales, ninguna localidad parece destacarse significativamente al respecto como se puede verificar en el cuadro siguiente:

Repartición de los corresponsales por localidad

\begin{tabular}{|c|c|c|c|c|c|}
\hline Localidad & Provincia & $\begin{array}{l}\text { número de } \\
\text { habitantes }\end{array}$ & láicos & $\begin{array}{l}\text { eclesiás- } \\
\text { ticos }\end{array}$ & $\begin{array}{c}\mathrm{n}^{\circ} \text { total de } \\
\text { corresp. }\end{array}$ \\
\hline Alanis & Sevilla & 1.431 & 0 & 1 & 1 \\
\hline Alba de Tormes & Salamanca & 2.468 & 0 & 1 & 1 \\
\hline Alcaraz & La Mancha & 7.690 & 1 & 0 & 1 \\
\hline
\end{tabular}

103. El corpus utilizado consta de 152 individuos (o sea el $81,7 \%$ de los corresponsales): no incluye ni a Francisco Xavier de Echaide que residía en Villalba, localidad que no hemos podido localizar con exactidumbre (véase supra), ni a otro corresponsal (anónimo) presentado tan sólo como hacendado de Andalucía.

104. Semanario de Agricultura..., 1806, tomo XX, pp. 407-417.

105. Sobre la distribución geográfica de los suscriptores del periódico, véase en LARRIBA, Elisabel, Le Public de la presse en Espagne à la fin du XVIII siècle (1780-1808), pp. 74-77.

106. Véase al respecto, "Bilan de la première partie", in LARRIBA, Elisabel, Le Public de la presse en Espagne à la fin du XVIII siècle (1780-1808), pp. 97-116. 


\begin{tabular}{|c|c|c|c|c|}
\hline Alcoy & Valencia & 11.434 & 1 & 0 \\
\hline Aldeanueva de la Vera & Extremadura & 1.265 & 1 & 0 \\
\hline Almagro & La Mancha & 9.609 & 0 & 1 \\
\hline Alvelda de Iregua & Soria & 697 & 1 & 0 \\
\hline Ampudia & Palencia & 1.603 & 1 & 0 \\
\hline Ardales & Sevilla & 971 & 0 & 1 \\
\hline Astorga & León & 2.827 & 1 & 0 \\
\hline Azpeitia & Guipúzcoa & 4.894 & 1 & 0 \\
\hline Beizama & Guipúzcoa & 692 & 0 & 1 \\
\hline Belmonte & La Mancha & 2.636 & 1 & 0 \\
\hline Bernui de Coca & Segovia & 284 & 0 & 1 \\
\hline Blocona & Soria & 202 & 0 & 1 \\
\hline Boos & Soria & 238 & 0 & 1 \\
\hline Cádiż & Sevilla & 71.080 & 1 & 0 \\
\hline Calahorra & Soria & 5.117 & 0 & 1 \\
\hline Camporreal & Toledo & 1.212 & 1 & 0 \\
\hline Cañaveral & Extremadura & 232 & 1 & 0 \\
\hline Castrodeza & Valladolid & 736 & 1 & 0 \\
\hline Cereceda de la Sierra & Salamanca & 285 & 0 & 1 \\
\hline Ciudad Rodrigo & Salamanca & 5.637 & 1 & 0 \\
\hline Cizurquil & Guipúzcoa & 883 & 0 & 1 \\
\hline Coronada de la Serena & Extremadura & 964 & 1 & 0 \\
\hline Coruña & Galicia & 13.575 & 1 & 0 \\
\hline Ejea de los Caballeros & Aragón & 2.673 & 1 & 0 \\
\hline Escalonilla & Toledo & 1.409 & 0 & 1 \\
\hline Fresnillo de las Dueñas & Burgos & 394 & 0 & 1 \\
\hline Gargoles de Abajo & Guadalajara & 391 & 1 & 0 \\
\hline Granada & Granada & 56.541 & 1 & 0 \\
\hline Guarroman & Nuevas Pob. & 594 & 0 & 1 \\
\hline Guetadar & Navarra & 82 & 0 & 1 \\
\hline Hoz de Barbastro & Aragón & 267 & 0 & 1 \\
\hline Huercal Obera & Granada & 8.285 & 1 & 0 \\
\hline Jerez de los Caballeros & Extremadura & 1.081 & 1 & 0 \\
\hline Lagunilla de Jubera & Burgos & 797 & 0 & 1 \\
\hline Lascellas & Aragón & 207 & 1 & 0 \\
\hline Leganiel & Cuenca & 993 & 0 & 1 \\
\hline Lérida & Cataluña & 10.714 & 1 & 0 \\
\hline Lima & América & - & 1 & 0 \\
\hline Linares & Salamanca & 903 & 0 & 1 \\
\hline Málaga & Granada & 51.098 & 1 & 0 \\
\hline Manganes de Polvorosa & Valladolid & 470 & 0 & 1 \\
\hline Meruelo & Burgos & 829 & 1 & 0 \\
\hline Molinos de Duero & Soria & 243 & 1 & 0 \\
\hline Montuenga & Avila & 258 & 0 & 1 \\
\hline Morata de Jalón & Aragón & 1.387 & 1 & 0 \\
\hline Naval & Aragón & 909 & 1 & 0 \\
\hline Navas del Madroño & Extremadura & 2.182 & 1 & 0 \\
\hline Navin & Galicia & & 1 & 0 \\
\hline Ochandiano & Vizcaya & 1.188 & 1 & 0 \\
\hline Orcera & Murcia & 1.114 & 0 & 1 \\
\hline Peraleja, la & Cuenca & 794 & 0 & 1 \\
\hline Piedralba (Astorga) & León & 122 & 0 & 1 \\
\hline Plasencia & Extremadura & 4.852 & 0 & $i$ \\
\hline Poblachuela & La Mancha & - & 0 & 1 \\
\hline Ponferrada & León & 1.552 & 1 & 0 \\
\hline Pozuelo de Alorcón & Madrid & 751 & 1 & 0 \\
\hline Quintanas de Gormaz & Soria & 393 & 1 & 0 \\
\hline Reinosa & Toro & 1.613 & 1 & 0 \\
\hline Revilla de Campo & Burgos & 457 & 1 & 0 \\
\hline S. Mamed de Salgueiros & Galicia & 180 & 0 & 1 \\
\hline Sadava & Aragón & 1.211 & 1 & 0 \\
\hline
\end{tabular}




\begin{tabular}{|c|c|c|}
\hline Salamanca & Salamanca & 19.092 \\
\hline Sallent & Cataluña & 138 \\
\hline San Juan de Collbre & Galicia & \\
\hline San Juan del Puerto & Sevilla & 1.710 \\
\hline Sax & Murcia & 2.164 \\
\hline Sayalonga & Granada & 627 \\
\hline Segovia & Segovia & 10.782 \\
\hline Segura & Guipúzcoa & 1.233 \\
\hline Sta Cruz de Mudela & La Mancha & 4.726 \\
\hline Talarrubias & Extremadura & 1.895 \\
\hline Tamarite de Litera & Aragón & 2.776 \\
\hline Taranes & Asturias & \\
\hline Tordehumos & Valladolid & 1.075 \\
\hline Torrelaguna & Toledo & 1.812 \\
\hline Torrubia del Campo & Toledo & 1.169 \\
\hline Tudelilla & Burgos & 618 \\
\hline Turienzo de los Caballeros & León & 268 \\
\hline Ubrique & Granada & 4.890 \\
\hline Valladolid & Valladolid & 23.284 \\
\hline Valls & Cataluña & 8.273 \\
\hline Viguera & Soria & 1.176 \\
\hline Villafranca del Penedes & Cataluña & 3.786 \\
\hline Villalba & - & \\
\hline Villamayor de Santiago & La Mancha & 2.398 \\
\hline Villanueva de los Infantes & Valladolid. & 125 \\
\hline Villar del Pedroso & Toledo & 793 \\
\hline Villarejo de Salvanes & Toledo & 2.509 \\
\hline Zalamea de la Serena & Extremadura & 2.832 \\
\hline Alcañiz & Aragón & 5.712 \\
\hline Ariza & Aragón & 1.135 \\
\hline Burgo de Osma & Soria & 2.167 \\
\hline La Haya & Suecia & \\
\hline Fontiyuelo de Campos & León & 401 \\
\hline Fonz & Aragón & 1.393 \\
\hline Nijar & Granada & 4.196 \\
\hline Sevilla & Sevilla & 80.915 \\
\hline Trebiana & Burgos & 724 \\
\hline Valencia & Valencia & 105.492 \\
\hline Yepes & Toledo & 3.445 \\
\hline Zafra & Extremadura & 5.633 \\
\hline Aranjuez & Reales Sitios & 2.653 \\
\hline Lucillos & Toledo & 574 \\
\hline Madrid & Madrid & 156.648 \\
\hline Barcelona & Cataluña & 33.244 \\
\hline Sanlucar de Barrameda & Sevilla & 14.840 \\
\hline Zaragoza & Aragón & 46.434 \\
\hline
\end{tabular}

\begin{tabular}{|c|c|c|}
\hline 1 & 0 & 1 \\
\hline 1 & 0 & 1 \\
\hline 1 & 0 & 1 \\
\hline 1 & 0 & 1 \\
\hline 0 & 1 & 1 \\
\hline 1 & 0 & 1 \\
\hline 1 & 0 & 1 \\
\hline 1 & 0 & 1 \\
\hline 1 & 0 & 1 \\
\hline 0 & 1 & 1 \\
\hline 1 & 0 & 1 \\
\hline 0 & 1 & 1 \\
\hline 1 & 0 & 1 \\
\hline 1 & 0 & 1 \\
\hline 1 & 0 & 1 \\
\hline 0 & 1 & 1 \\
\hline 0 & 1 & 1 \\
\hline 1 & 0 & 1 \\
\hline 1 & 0 & 1 \\
\hline 0 & 1 & 1 \\
\hline 1 & 0 & 1 \\
\hline 1 & 0 & 1 \\
\hline 1 & 0 & 1 \\
\hline 1 & 0 & 1 \\
\hline 0 & 1 & 1 \\
\hline 1 & 0 & 1 \\
\hline 1 & 0 & 1 \\
\hline 1 & 0 & 1 \\
\hline 2 & 0 & 2 \\
\hline 2 & 0 & 2 \\
\hline 1 & 1 & 2 \\
\hline 2 & 0 & 2 \\
\hline 1 & 1 & 2 \\
\hline 2 & 0 & 2 \\
\hline 2 & 0 & 2 \\
\hline 1 & 1 & 2 \\
\hline 2 & 0 & 2 \\
\hline 2 & 0 & 2 \\
\hline 2 & 0 & 2 \\
\hline 2 & 0 & 2 \\
\hline 3 & 0 & 3 \\
\hline 2 & 1 & 3 \\
\hline 3 & 0 & 3 \\
\hline 2 & 2 & 4 \\
\hline 4 & 0 & 4 \\
\hline 3 & 1 & 4 \\
\hline 96 & 41 & 137 \\
\hline
\end{tabular}

FUENTES: la correspondencia publicada en el Semanario de Agricultura y Artes... y el Censo de Floridablanca. Madrid 1787.

Así, de las 110 localidades contabilizadas, 92 (o sea el 83,6\%) albergaban a un colaborador único. En otras 12 (el $10,9 \%$ ) los redactores disponían de 2 corresponsales. En Aranjuez, Lucillos y Madrid, su número era de 3 y éste alcanzó un máximo de tan sólo 4 en Barcelona, Sanlucar de Barrameda y Zaragoza. Con lo cual, si las cartas publicadas en el periódico tuvieron a menudo un impacto nada desdeñable sobre el público y pudieron favorecer el aumento del número de lectores, éstas, por regla general, no suscitaron, a nivel local 
y por lo que a corresponsales se refiere, un clima de emulación lo que deploraron sin lugar a dudas los responsables de la obra.

Sin embargo, entre sus motivos de satisfacción figuraba el haber conseguido establecer un diálogo epistolar con lectores que residían en localidades de importancia muy variada en cuanto al número de habitantes como se puede comprobar en el siguiente cuadro establecido a partir de un corpus compuesto de 103 poblaciones (el $93,6 \%$ de las mencionadas) entre las cuales se repartían 129 corresponsales (o sea el $70 \%$ de ellos):

Clasificación de las localidades en función del número de habitantes

\begin{tabular}{|l|c|c|c|c|}
\hline $\mathrm{n}^{\circ}$ de habitantes & $\begin{array}{c}\mathrm{n}^{\circ} \text { de } \\
\text { localidades }\end{array}$ & láicos & eclesiásticos & $\begin{array}{c}\mathrm{N}^{\circ} \text { total de } \\
\text { corresponsales }\end{array}$ \\
\hline$<100$ & 1 & 0 & 1 & 1 \\
\hline entre 100 y 500 & 20 & 8 & 13 & 21 \\
\hline entre 500 y 1000 & 19 & 12 & 10 & 22 \\
\hline entre 1000 y 5000 & 40 & 39 & 8 & 47 \\
\hline entre 5000 y 10000 & 8 & 7 & 3 & 10 \\
\hline entre 10000 y 50000 & 9 & 15 & 3 & 18 \\
\hline entre 50000 y 100000 & 4 & 4 & 1 & 5 \\
\hline$>100000$ & 2 & 5 & 0 & 5 \\
\hline Total & 103 & 90 & 39 & 129 \\
\hline
\end{tabular}

FUENTES: la correspondencia publicada en el Semanario de Agricultura y Artes... y el Censo de Floridablanca. Madrid 1787.

El número de habitantes de las localidades referidas oscila entre un máximo de 156648 para Madrid y un mínimo de 82 para Guetadar, lugar de Navarra donde el abad Antonio Bariain remitió en mayo de 1804 una carta sobre el modo utilizado en su región para salar los jamones ${ }^{107}$. Lector apasionado del periódico que recibía por suscripción ${ }^{108}$, ese eclesiástico (al cual los redactores no dudaron en mandar varias semillas) dedicaba parte de su tiempo a dar a conocer en su humilde parroquia los saberes proporcionados por el Semanario de Agriculturas y Artes... ${ }^{109}$. Sin lugar a dudas los editores habían hallado en él

107. "Modo de salar los jamones en Navarra - Extracto de una carta de D. Antonio Bariain, Abad de Guetadar", in Semanario de Agricultura..., tomo XV, n 387, 31 de mayo de 1804, p. 352 .

108. Figura en la lista de suscriptores publicada en 1806.

109. "Modo de salar los jamones en Navarra...": "Señores editores: Al mismo tiempo que procuro aprovecharme y que se aprovechen mis feligieses de las lecciones que nos da el Semanario de agricultura, y de las semillas que se han servido franquearme, desearía contribuir a la extensión de los conocimientos útiles, y con este objeto expresaré el método que uso en mi casa para salar los jamones, y que han adoptado ya muchas personas de gusto delicado..." 
un activo colaborador en su intento de difundir las luces por toda España sin excluir, como tan a menudo se había hecho, "las aldeas y pueblos pequeños, en donde suelen faltar medios y luces para mejorar la suerte de sus habitantes $^{\prime \prime 110}$. Al igual que Antonio Bariain varios de los corresponsales del periódico (sin ser mayoritarios) procedían de localidades poco o medianamente populosas. Efectivamente 44 (o sea, el 34,1\%) residian en poblaciones que contaban con menos de 1000 habitantes. Entre ellos 20 láicos y 24 eclesiásticos que representaban el $22 \%$ y el $61,5 \%$ de sus grupos respectivos. $Y$ esta tendencia se inversa con el aumento del número de vecinos hasta tal punto que entre los 5 corresponsales establecidos en ciudades con más de 100000 almas no figuraba ningún representante de la Iglesia. Con lo cual, si los resultados obtenidos no debieron satisfacer por completo a los redactores, demostraron a lo menos que su elección del clero, y principalmente del clero parroquial, como agente transmisor podía efectivamente contribuir a romper el tremendo aislamiento cultural que padecía el mundo rural.

Los editores, que concibieron el periódico como una obra de utilidad pública que había de beneficiar a todos con la ayuda de todos, fuese cual fuera su condición y su procedencia geográfica, habían logrado constituir una apreciable red de corresponsales que, sin ser, ni mucho menos, lectores asiduos de prensa, aceptaron gustosos el papel que se les proponía. Así de los 82 individuos identificados por sus nombres y apellidos tan sólo 7 se suscribieron a un periódico que no fuera el Semanario de Agricultura y Artes... Josef Gonzalez Laso (obispo de Plasencia), Josef Antonio Olano (vicario de Cizurquil en Navarra) y Luis Carlos y Zuñiga (cura párroco de Escalonilla, en la provincia de Toledo) figuraban entre los abonados del Memorial literario: el primero en 1785, el segundo en 1786 y el último en 1794"'. Judas Josef Cabriada y Zedezero (capeIlán de Calahorra) había encargado en 1788 el Semanario erudito ${ }^{112}$ y el Espíri-

110. Carta del Príncipe de la Paz a los obispos, San Lorenzo, 28 de noviembre de 1796, in Semanario de Agricultura..., 1797, tomo I, pp. IV-V (o p. 70 de nuestra antología): "Siempre ha visto el Rey con sentimiento que la muy apreciable clase de labradores esté abandonada a sus escasos conocimientos en la agricultura, y que todos los cuidados, los auxilios y establecimientos benéficos se prodiguen en las ciudades, como si ellas solas fuesen los pueblos privilegiados que mereciesen toda la atención del gobierno, y no debiese ésta recaer más bien sobre las aldeas y pueblos pequeños, en donde suelen faltar medios y luces para mejorar la suerte de sus habitantes."

111. Véanse las listas de suscriptores publicadas en el Memorial literario (Madrid) en noviembre de 1785 (tomo VI, pp. 398-405), en abril de 1786 (tomo VII, pp. 558-564) y en 1794 (tomo IV, parte I, pp. 225-238).

112. Véase la lista de suscriptores publicada en el Semanario erudido, Madrid, tomo IX, pp. I-XVIII. 
tu de los mejores Diarios literarios que se publican en Europa ${ }^{113}$. Entre los láicos, Roberto de Armesto y Silva "apasionado y constante suscriptor" del Semanario de Agricultura y Artes... ${ }^{114}$ se interesó también, en 1786, por el Memorial literario ${ }^{115}$, fecha en que ejercía como oficial de la marina en el despacho del Ferrol ${ }^{116}$. Joseph de Tena Godoy y Malfeito, abogado de los Reales Consejos, que remitió desde Zalamea de la Serena (Extremadura) varias cartas a los redactores $^{117}$, se abonó en 1790 a La Espigadera ${ }^{118}$ y en 1793 al Memorial literario ${ }^{119}$. Finalmente, y a diferencia de éstos, Serapio Sinues, catedrático de Agricultura y miembro de la Real Sociedad Aragonesa de Amigos del País, poco sensible a la prensa de índole literaria, recibía en 1792 el Correo mercantil de España y sus Indias ${ }^{120}$. Al igual que este especialista de las cuestiones agrarias, la mayoría de los corresponsales del Semanario... no buscaba en la prensa un mero recurso para hallar un barniz cultural a poco costa o satisfacer su curiosidad intelectual. Su adhesión al periódico, percibido ante todo como una fuente de informaciones prácticas y como un lugar de intercambio abierto a todos, derivaba principalmente de un verdadero interés por la agricultura, las artes o cuanto podía favorecer una mejora económica. Ahora bien, la importancia impartida al diálogo con el público y la amenidad que caracterizaban la obra

113. Véase la lista de suscriptores publicada en el Espíritu de los mejores Diarios. Dedicado a los literatos y curiosos de España. Que contiene las principales noticias que ocurren en las Ciencias, Artes, Literatura y Comercio; varias anécdotas curiosas, el anuncio de las obras que se publican, las invenciones que se hacen y los adelantamientos de las Ciencias, Madrid, tomo III, $n^{\circ} 134,23$ de junio de 1788, pp. 87-96.

114. Dato que viene confirmado por la lista de suscriptores publicada en 1806 por el Semanario de Agricultura...

11.5. Véase la lista de suscriptores publicada en abril de 1786 por el Memorial literario, tomo VII, pp. 558-564.

116. Véase la lista de suscriptores publicada en abril de 1786 por el Memorial literario, tomo VII, pp. 558-564.

117. Los redactores publicaron 7 de las cartas remitidas por Joseph de Tena Godoy y Malfeito que, según los artículos, viene identificado por sus nombres y apellidos, por las iniciales J.M., J.T.G. y M. o es presentado tan sólo como "un suscriptor de Zalamea": "Carta de un suscriptor de Zalamea - Veterinaria", in Semanario de Agricultura..., tomo III, $n^{\circ} 63,15$ de marzo de 1798, pp. 163-164; "Carta sobre el destete de potros - Veterinaria", tomo III, n 70, 3 de mayo de 1798, pp. 286-287; "Carta sobre el pan de patatas", tomo IV, $n^{\circ} 85,16$ de agosto de 1798, pp. 111-112; "Carta sobre el cultivo del panizo", tomo IV, $n^{\circ} 103,20$ de diciembre de 1798, pp. 385-390; "Carta sobre una observación curiosa", tomo XI, n²80, 13 de mayo de 1802, p. 304; "Extracto de una carta sobre la langosta de Extremadura, sus daños y remedios", tomo XIII, $n^{\circ} 330,28$ de abril de 1803, pp. 257-263 y "Carta de criar los potros sin que mamen", tomo XVI, $n^{\circ} 400,30$ de agosto de 1804, pp. 143-144.

118. Véase la lista de suscriptores publicada en La Espigadera, Madrid, 1790, tomo I, pp. 5-16.

119. Véase la lista de suscriptores publicada en el Memorial literario en 1793, tomo I, parte II, pp. 449-463.

120. Véase la lista de suscriptores publicada por el Correo mercantil de España y sus Indias, tomo I, cuaderno I (octubre a diciembre de 1792), pp. 3-17. 
y le conferian un cariz único (por lo menos hasta el cambio direccional de 1805) fueron igualmente determinantes y sedujeron a más de uno. Entre ellos un anónimo fabricante de chocolate que, prefiriendo la lectura de los romances y de las jácaras a la de los periódicos, llegó sin embargo a apasionarse por el Semanario de Agricultura y Artes...en que le llamaron la atención ante todo los artículos en relación con su profesión y la correspondencia remitida por lectores, lo que subrayó en su propia carta a los redactores: "Como mi librería -les escribía- por lo regular sólo contiene el Don Quijote, el Ejercicio cotidiano, y una porción bastante buena de romances y de jácaras, no les puedo ponderar a V.ms. cuanto ha sido mi complacencia al hallarme con unos papeles tan apreciables como los números del Semanario. Los he recorrido con una viveza increíble, y después de la composición del chocolate, llamaron todo mi cuidado algunas cartas..." ${ }^{\prime 21}$. El entusiasmo del que empezó utilizando el Semanario... tan sólo para envolver castañas de chocolate ${ }^{122}$, el importante número de los corresponsales del periódico así como la diversidad de ese colectivo tendían a demostrar la validez de la fórmula hallada por los redactores, unos redactores convencidos de que "en medio de la corrupción del Siglo en que vivimos, y en que no se ve más que egoísmo, hay todavía hombres a quienes no mueve ni la avaricia ni la ambición para hacer lo que pueden en beneficio de sus semejantes ${ }^{\prime \prime 23}$. Pero ello no era suficiente.

121. "Carta sobre la fabricación del chocolate", in Semanario de Agricultura..., tomo XXII, $\mathrm{n}^{\circ} 561,1$ de octubre de 1807, p. 212 :

122. "Carta sobre la fabricación del chocolate", pp. 209-210: "Quiero solamente que me tengan por lo que soy, por un fabricante de chocolate, en cuyas manos una casualidad ha puesto estos números con algunos otros de su periódico. Su primer destino había sido el de conservarlos para envolver castañas de chocolate: jtanto es el aprecio que nuestros Párrocos hacen de obra tan utilísima! Pero el haber visto que trataban de mi misma profesión, me excitó la curiosidad de leerlos, y de rescatarlos del oficio despreciable a que estaban reducidos siempre que conociese lo merecían. En efecto los he leído y vuelto a leer muchísimas veces, y a excepción de los reparillos que voy a hacer, y que a mí no me parecen mal fundados, los hallo de muchísima utilidad, infiriendo que toda esta obra puede ser el mejor y más rico tesoro para quien pueda y sepa hacer uso de ella."

123. "Diálogo entre D.C. y D.A. sobre el modo más conveniente de publicar el Semanario de Agricultura y Artes para que sea útil", tomo VII, $n^{\circ} 165,27$ de febrero de 1800, p. 144 (o pp. 138-139 de nuestra antología). 